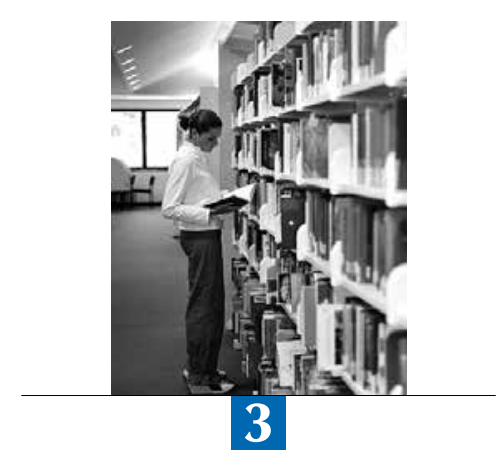

\title{
Measuring Opportunities to Learn Mathematics
}

This chapter examines whether and how exposure to mathematics content, known as "opportunity to learn", is associated with student performance. The analysis is based on students' responses to questions that appeared in the PISA Student Questionnaire on the degree to which they encountered various types of mathematics problems during their schooling, how familiar they were with certain formal mathematics content, and how frequently they had been taught to solve specific mathematics tasks involving formal or applied mathematics. 
Previous research has shown a relationship between students' exposure to subject content in school, what is known as "opportunity to learn", and student performance (e.g. Schmidt et al., 2001). Building on previous measures of opportunity to learn (Carroll, 1963; Wiley and Harnischfeger, 1974; Sykes, Schneider and Planck, 2009; Schmidt et al., 2001), the PISA 2012 assessment included questions to students on the mathematics theories, concepts and content to which they have been exposed to in school, and the amount of class time they spent studying this content.

\section{What the data tell us}

- Students in the high-performing East Asian countries and economies - Shanghai-China, Singapore, Hong Kong-China, Chinese Taipei, Korea, Macao-China and Japan - are more frequently exposed to formal mathematics than students in most of the other PISA-participating countries and economies.

- Exposure to more advanced mathematics content, such as algebra and geometry, appears to be related to high performance on the PISA mathematics assessment, even if the causal nature of this relationship cannot be established.

- Strong mathematics performance in PISA is not only related to opportunities to learn formal mathematics, such as solving a quadratic equation, using complex numbers, or calculating the volume of a box, but also to opportunities to learn applied mathematics (using mathematics in a real-world context).

Six questions were created in the Student Questionnaire to cover both the content and time aspects of students' opportunity to learn.

Four of the questions focused on the degree to which students encountered various types of mathematics problems or tasks during their schooling, which all form part of the PISA mathematics framework and assessment. Some of the tasks included in those questions involved formal mathematics content, such as solving an equation or calculating the volume of a box (see Question 4 at the end of this chapter). Others involved using mathematics in a real-world applied context (see Question 6 at the end of this chapter). Another type of task required using mathematics in its own context, such as using geometric theorems to determine the height of a pyramid (see Question 5 at the end of this chapter). The last type of tasks involved formal mathematics, but situated in a word problem like those typically found in textbooks (see Question 3 at the end of this chapter) where it is obvious to students what mathematics knowledge and skills are needed to solve them. Students were asked to indicate how frequently they encountered similar tasks in their mathematics lessons using a four-point scale: never, rarely, sometimes, or frequently.

In another question, students were asked how familiar they were with certain formal mathematics content, including such topics as quadratic functions, radicals and the cosine of an angle (see Question 2 at the end of this chapter). Responses to these tasks were recorded on a five-point scale indicating the degree to which students had heard of the topic. Having heard of a topic more often was assumed to reflect a greater degree of opportunity to learn.

In addition, a question asked students to indicate, on a four-point scale, how frequently they had been taught to solve eight specific mathematics tasks (see Question 1 at the end of this chapter). These tasks included both formal and applied mathematics.

All but the last question were used to create three indices: "formal mathematics", "word problems", and "applied mathematics". Values of these indices range from 0 to 3, indicating the degree of exposure to opportunity to learn, with 0 corresponding to no exposure and 3 to frequent exposure. (For more details on how these indices are constructed, see the section in blue at the end of this chapter.). When interpreting these data, it needs to be borne in mind that the 15 -year-olds assessed by PISA are, in some countries, dispersed over a range of grades and mathematical programmes and will therefore be exposed to a range of mathematical content.

On average, 15-year-olds in OECD countries indicated that they encounter applied mathematics tasks and word problems "sometimes" and formal mathematics tasks somewhat less frequently (Figures I.3.1a, b, c and Table I.3.1). 


\section{Students' exposure to word problems}

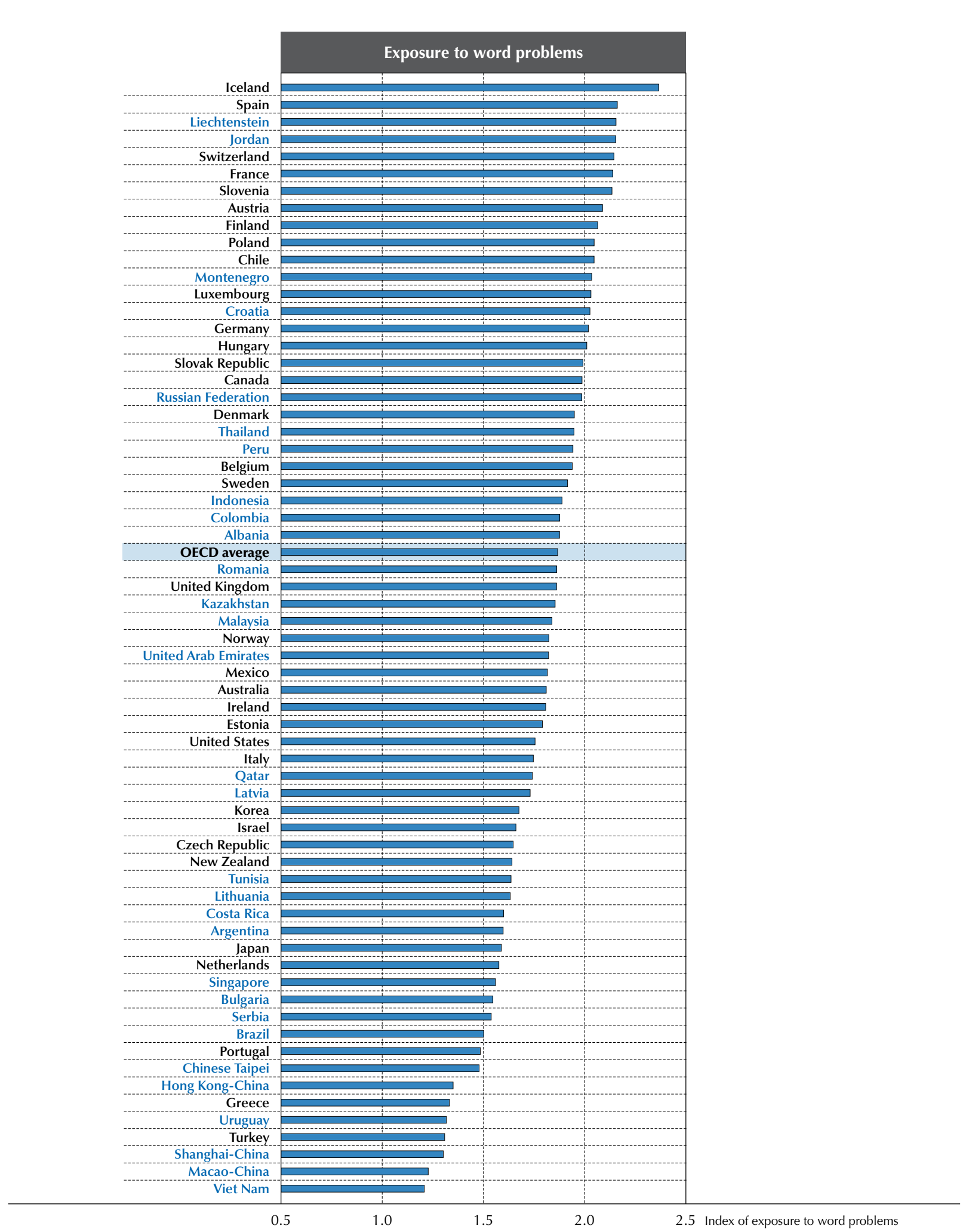

Countries and economies are ranked in descending order of the index of exposure to word problems.

Source: OECD, PISA 2012 Database, Table I.3.1.

StatLink 解估 http://dx.doi.org/10.1787/888932935591 


\section{Students' exposure to formal mathematics}

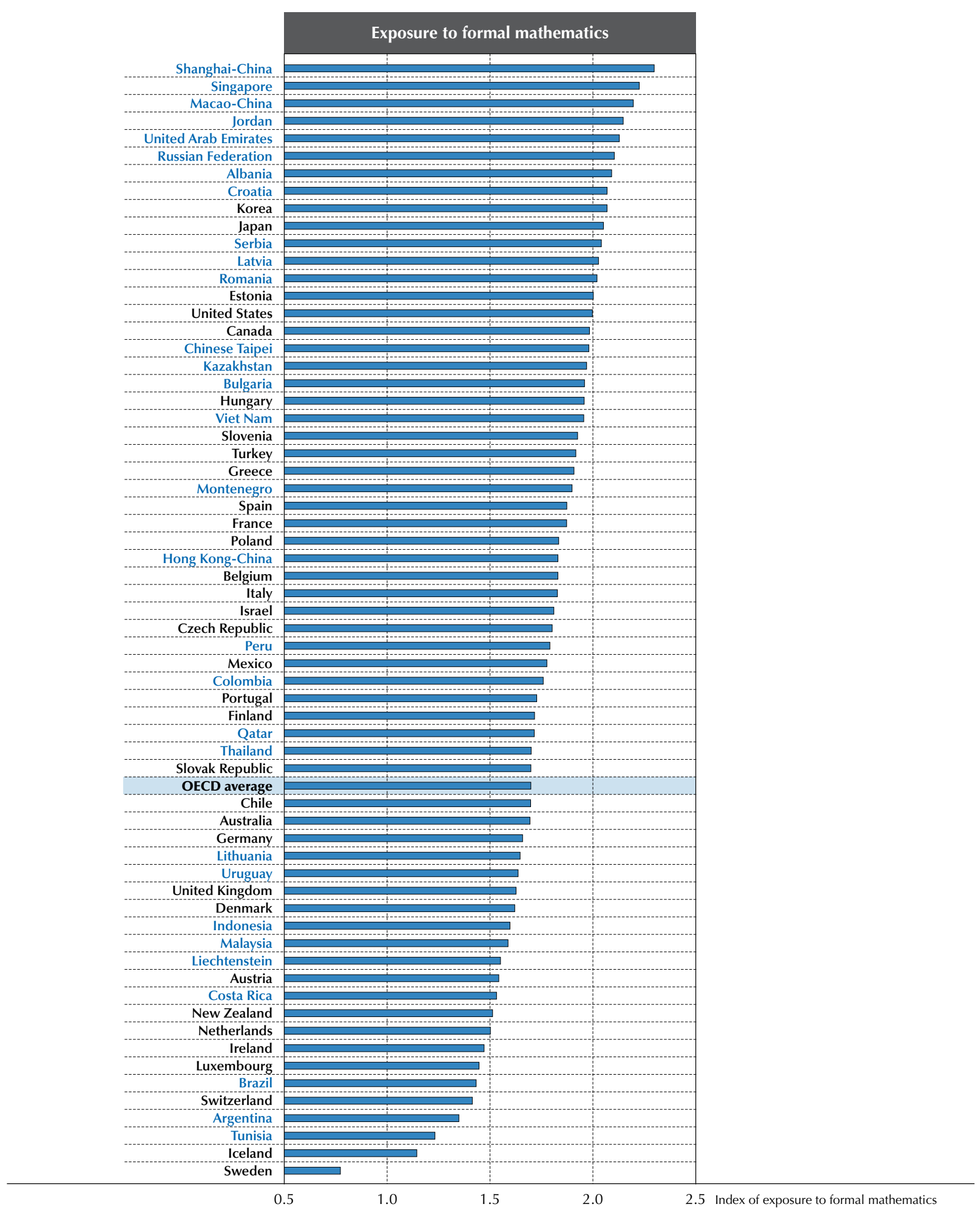

Countries and economies are ranked in descending order of the index of exposure to formal mathematics. Source: OECD, PISA 2012 Database, Table I.3.1.

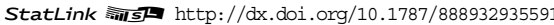




\section{Students' exposure to applied mathematics}

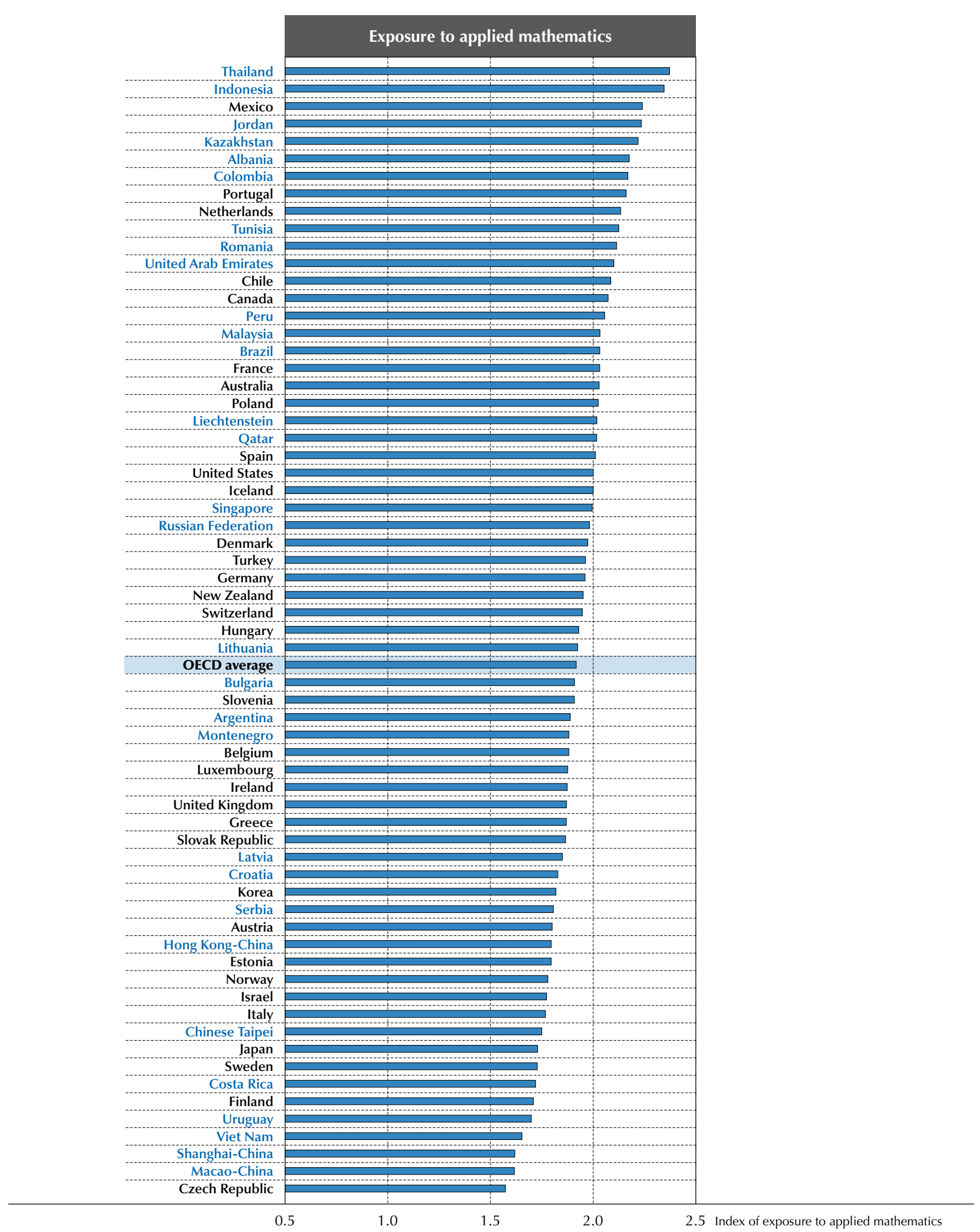

Countries and economies are ranked in descending order of the index of exposure to applied mathematics. Source: OECD, PISA 2012 Database, Table I.3.1.

StatLink त्नाज्ञ http://dx.doi.org/10.1787/888932935591 


\section{OPPORTUNITY TO LEARN AND STUDENT ACHIEVEMENT}

To examine the overall relationship between opportunity to learn and achievement, a three-level model was fitted to the data showing that at all three levels - country, school and student - there was a statistically significant relationship between opportunity to learn and student performance. Therefore, examinations of the relationship between opportunity to learn and achievement can be made at student, school and country levels simultaneously.

For applied mathematics, the relationship at all three levels is curvilinear (e.g. quadratic): on average, the more frequently students are exposed to problems involving applied mathematics, the better their mathematics performance, but only up to a point; after this point, performance declines. Figure I.3.2 graphically portrays the nature of the relationship averaged over the 65 countries, as well as over the OECD countries.

- Figure 1.3.2

Relationship between mathematics performance and students' exposure to applied mathematics

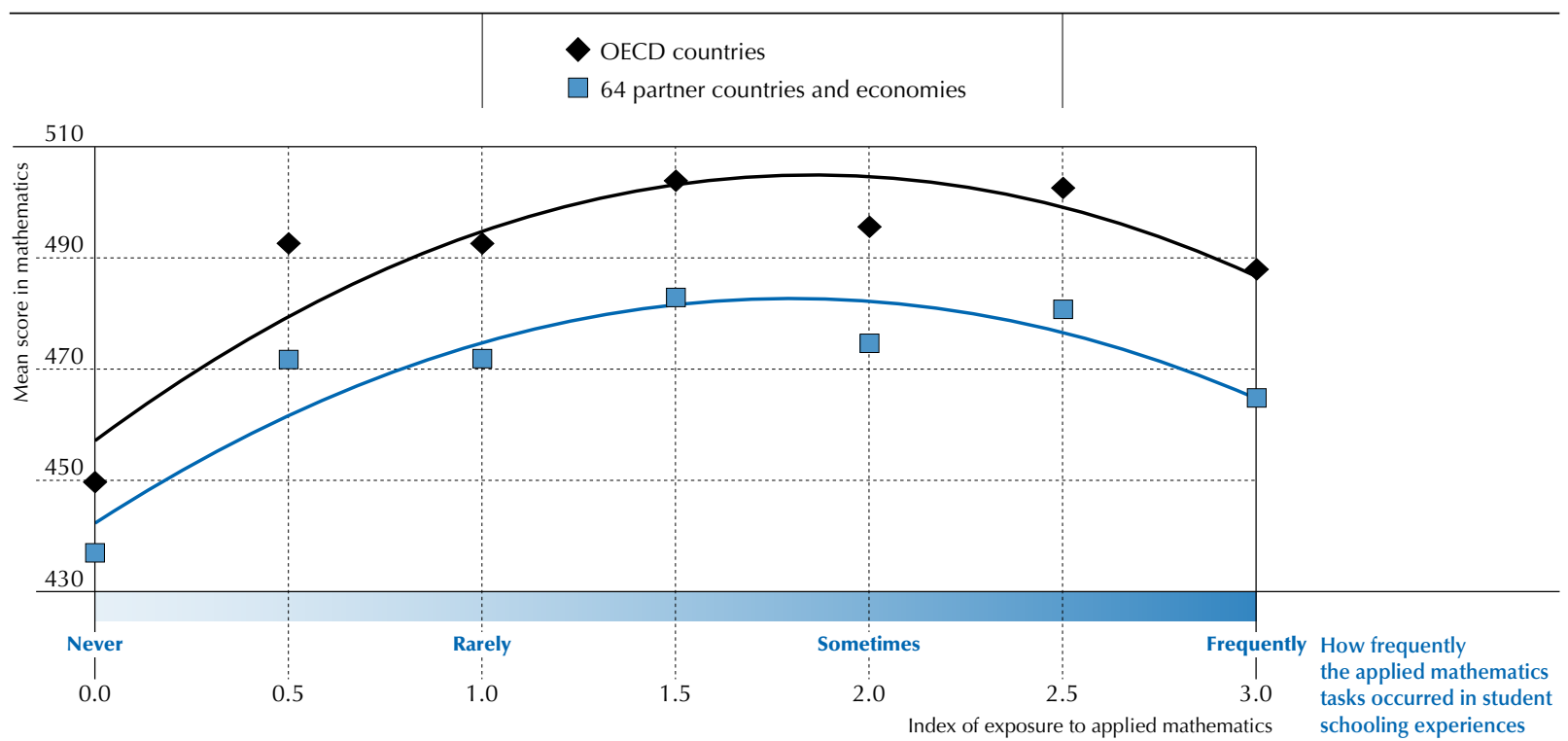

Source: OECD, PISA 2012 Database.

StatLink 而正 http://dx.doi.org/10.1787/888932935591

Among OECD countries, student performance is higher by about 40 points as the frequency of the encounters increased from "never" to "rarely"; but at a point between "rarely" and "sometimes" student performance reached a peak after which more frequent encounters with such problems had a negative relationship to performance. Fifteen-year-olds who frequently encounter applied problems scored about ten PISA score points below students who sometimes encounter such problems.

For both of the other opportunity-to-learn variables, i.e. word problems and formal mathematics - the relationship is linear. Exposure to word problems is positively related to performance at both the school and student levels, but not at the country level; the relationship between exposure to formal mathematics and performance is significant at all three levels.

Within each country the relationship between opportunity to learn and performance can be observed at both the school and student levels. These relationships were analysed using a two-level model. Of the 64 countries and economies that participated in PISA 2012 with available data for the index of opportunity to learn formal mathematics, all but Albania and Liechtenstein show a positive and statistically significant relationship between exposure to formal mathematics and performance at both the student and school levels (Figure 1.3.3). Among the OECD countries, the average impact of the degree of exposure to algebra and geometry topics on performance is around 50 points at the student level (i.e. increase in PISA mathematics score associated with one unit increase in the index of exposure to formal mathematics). The student level impact of the degree of exposure to word problems on performance is more limited, involving 49 countries with an OECD average estimated impact of 4 points (Table I.3.2). 
- Figure I.3.3 -

Country-level regressions between opportunity to learn variables and mathematics performance at the student and school levels

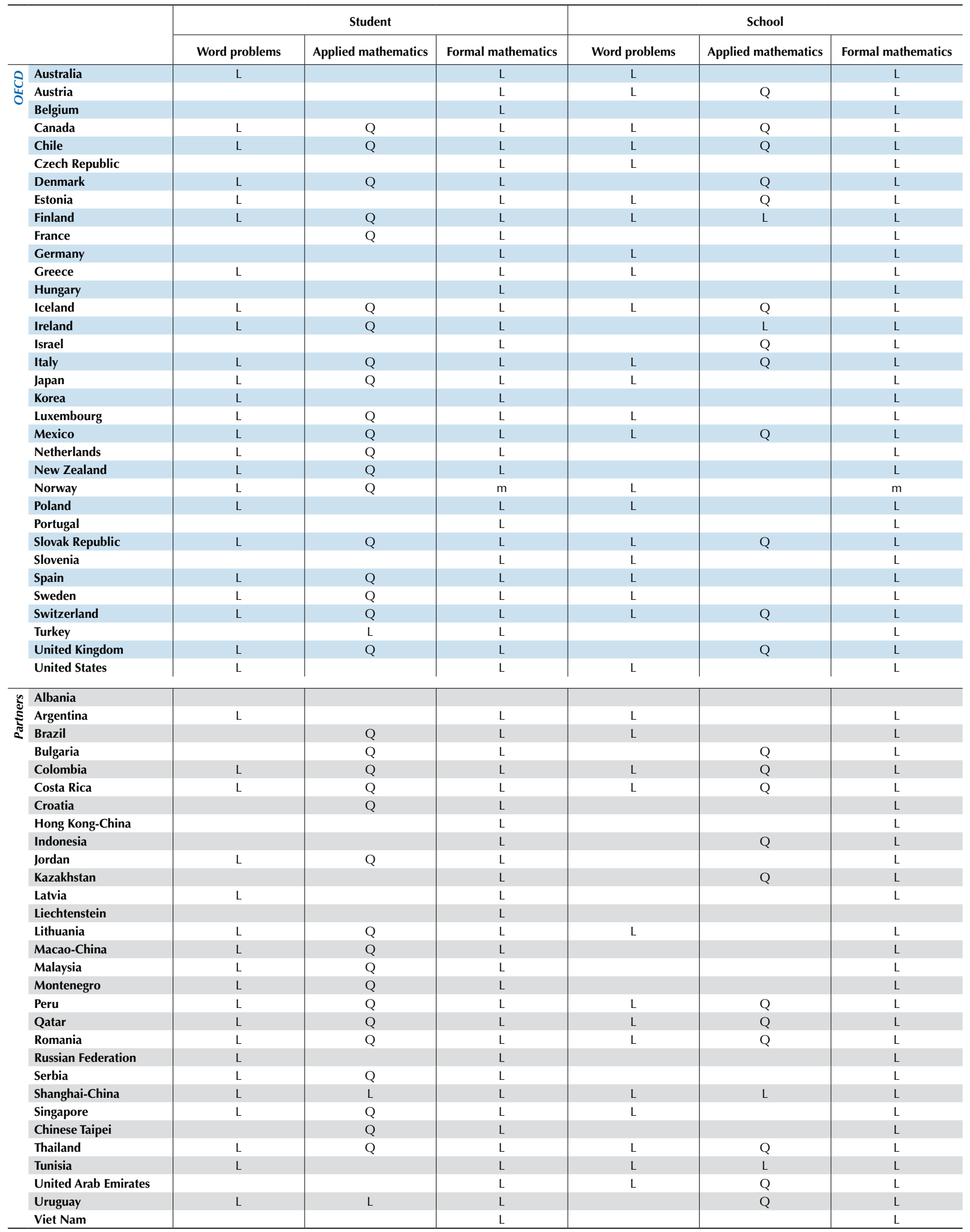

Note: " $\mathrm{L}$ " and "Q" show a statistically significant relationship between the opportunity to learn variables and mathematics performance. " $\mathrm{L}$ " when the relationship is linear and "Q" when it is quadratic.

Source: OECD, PISA 2012 Database, Table I.3.2.

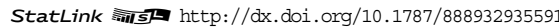


- Figure 1.3.4a

Relationship between the index of exposure to word problems and students' mathematics performance

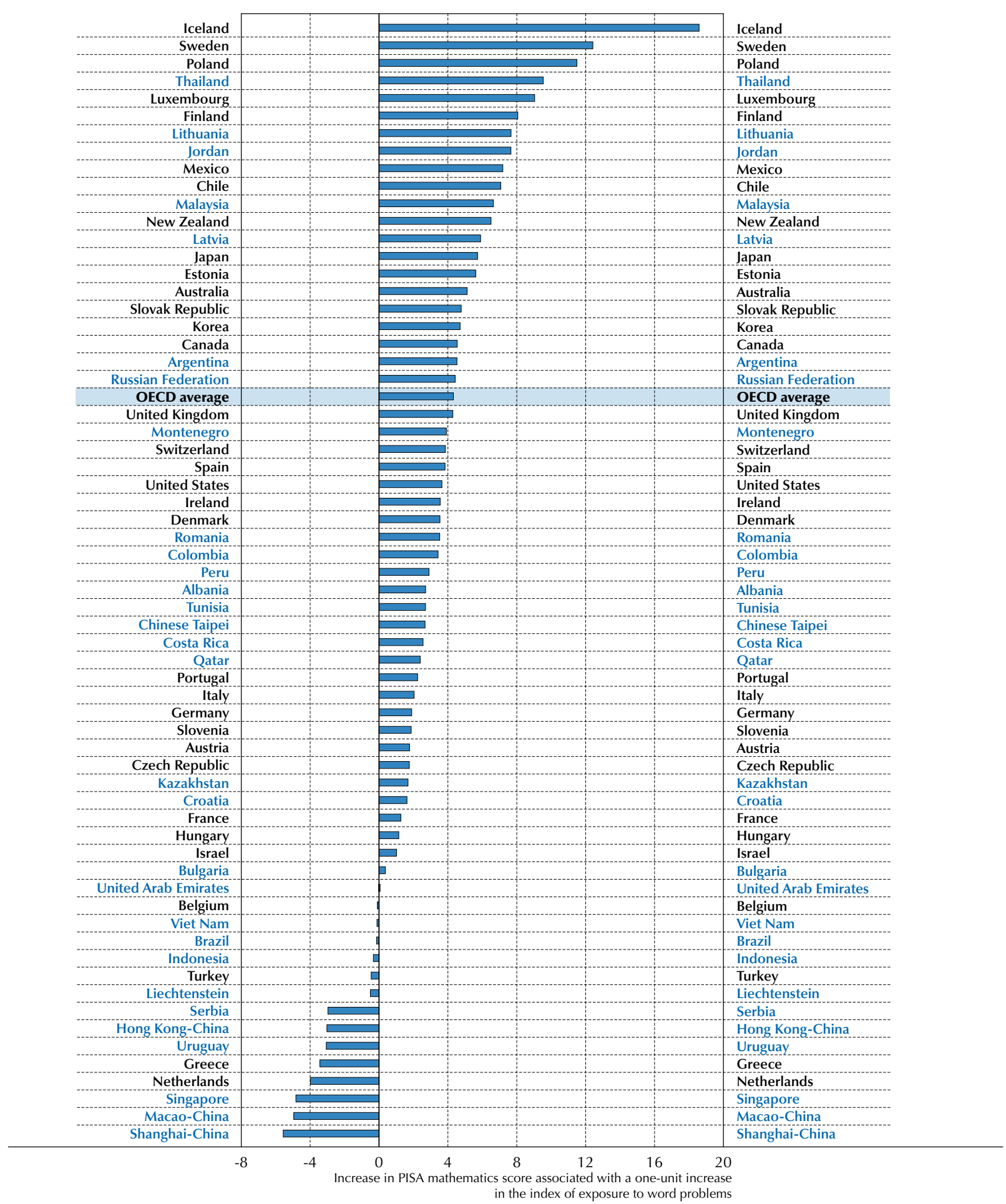

Note: For the index of exposure to word problems the estimates come from a linear regression, positive values thus signal that greater exposure is more strongly associated with students' mathematics performance.

Countries and economies are ranked in descending order of the strength of the relationship between the index of exposure to word problems and mathematics performance.

Source: OECD, PISA 2012 Database, Table 1.3.2.

StatLink त्माजा http://dx.doi.org/10.1787/888932935591 
- Figure $1.3 .4 \mathrm{~b}$ -

Relationship between the index of exposure to formal mathematics and students' mathematics performance

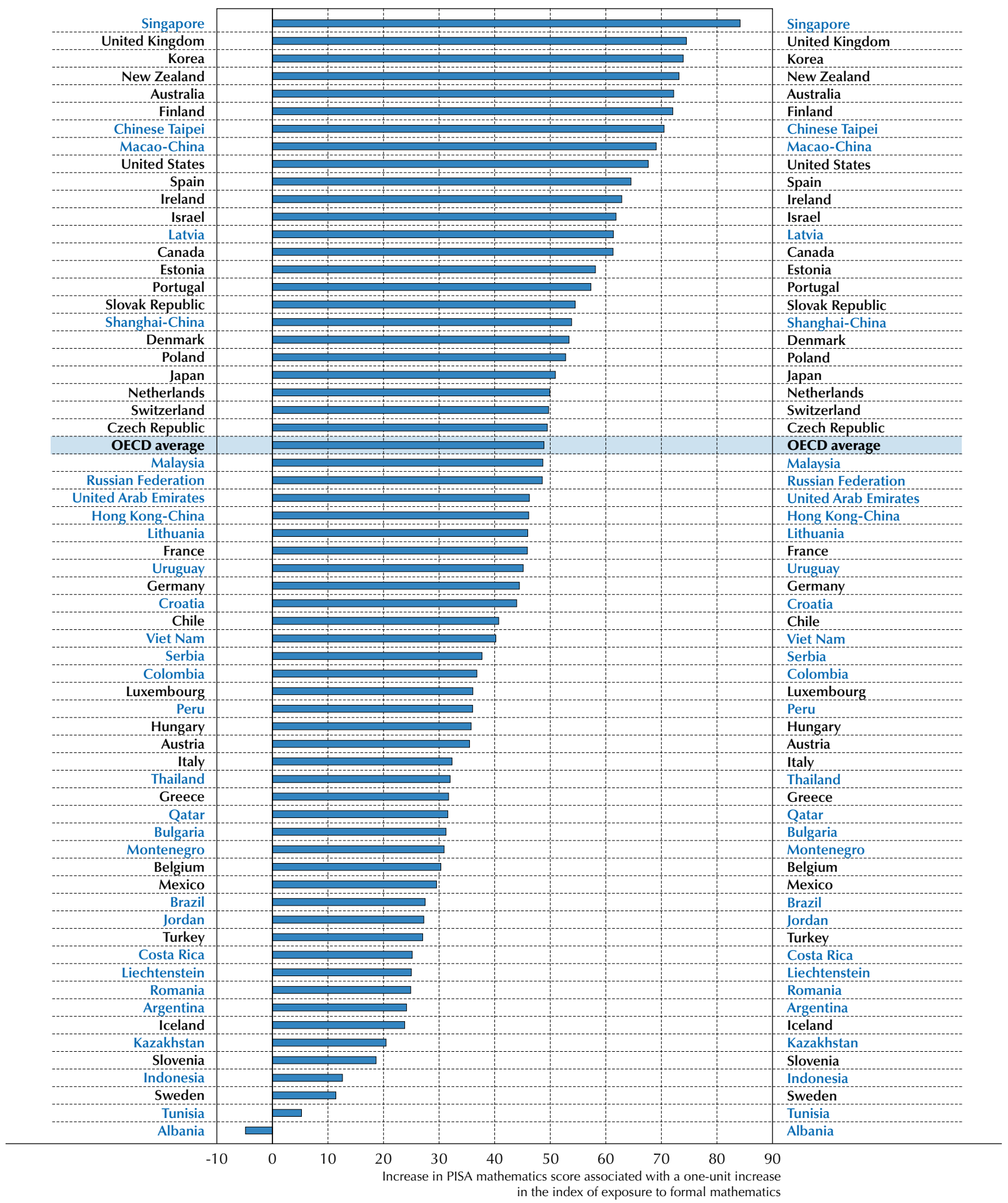

Note: For the index of exposure to formal mathematics the estimates come from a linear regression, positive values thus signal that greater exposure is more strongly associated with students' mathematics performance.

Countries and economies are ranked in descending order of the strength of the relationship between the index of exposure to formal mathematics and mathematics performance.

Source: OECD, PISA 2012 Database, Table 1.3.2.

StatLink न्नाड़ा http://dx.doi.org/10.1787/888932935591 
- Figure I.3.4c

\section{Relationship between the index of exposure to applied mathematics and students' mathematics performance}

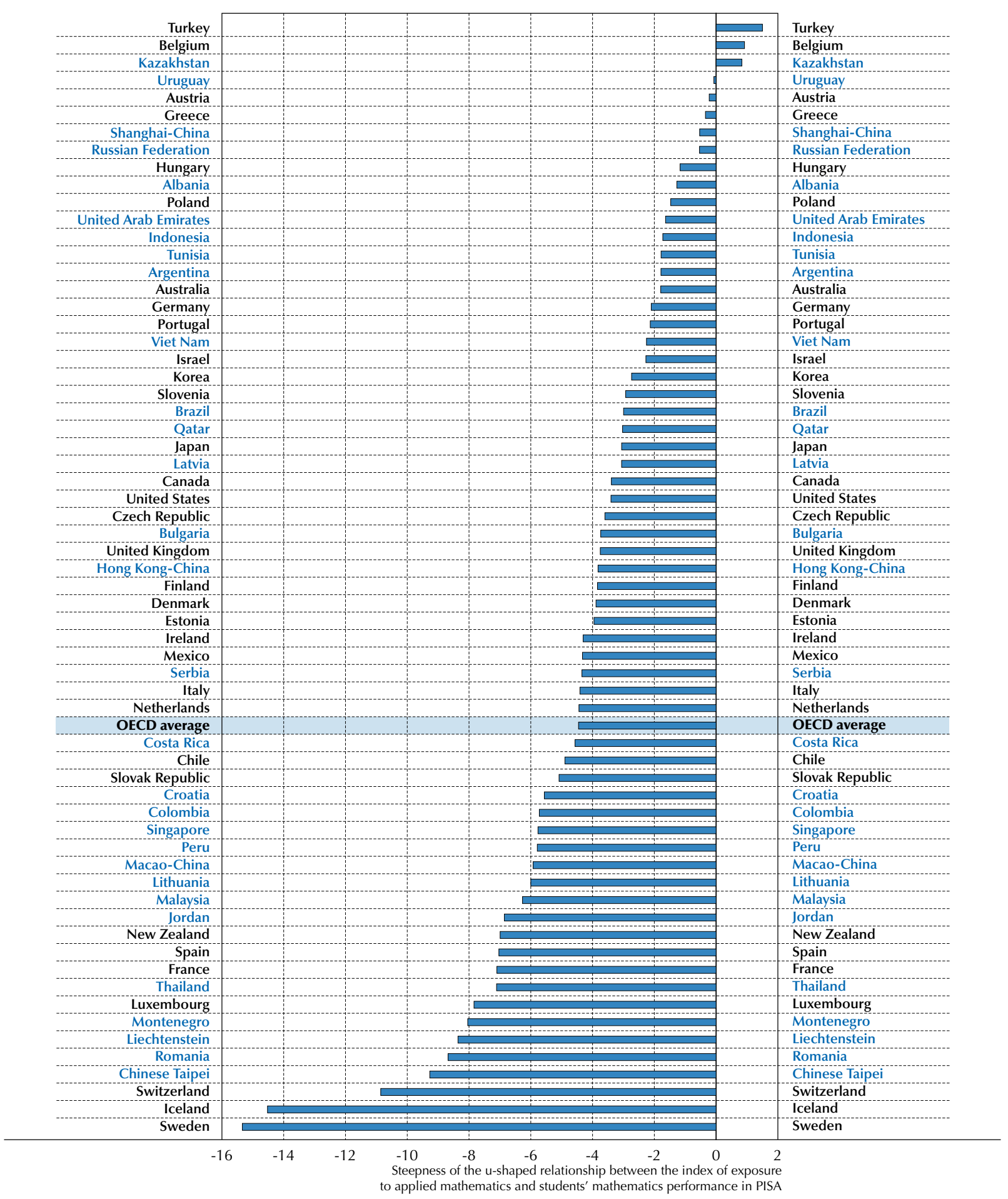

Note: For the index of exposure to applied mathematics the estimates are from a regression with a quadratic term, meaning that negative values indicate an inverted-u shape relationship between the index and students' mathematics performance. Lower negative numbers point to steeper inverted u-shaped relationships. Countries and economies are ranked in descending order of the strength of the relationship between the index of exposure to applied mathematics and mathematics performance.

Source: OECD, PISA 2012 Database, Table I.3.2.

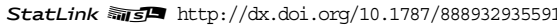


It is noteworthy that in the high-performing East Asian countries and economies on the PISA assessment - ShanghaiChina, Singapore, Hong Kong-China, Chinese Taipei, Korea, Macao-China and Japan - the exposure to formal mathematics is significantly stronger than in the remaining PISA participating countries and economies (2.1 versus 1.7$)$. The exposure to word problems shows the opposite pattern. In this case the exposure to word problems is less strong in the high-performing East Asian countries and economies than in the other countries (1.4 versus 1.8). For the index of exposure to applied mathematics, the difference between high-performing East Asian participants and other countries and economies is about 0.2 points (1.8 versus 2.0) (Table I.3.1).

The results suggest that opportunities to learn formal mathematics are related to PISA performance. Furthermore, exposure to more advanced mathematics content, such as algebra and geometry, appears to be related to high performance on the PISA mathematics assessment, even if the causal nature of this relationship cannot be established.

At the student level, the estimated effect of a greater degree of familiarity with such content on performance is almost 50 points (Figure I.3.4b and Table I.3.2). The results could indicate that students exposed to advanced mathematics content are also good at applying that content to PISA tasks. Alternatively, the results could indicate that high-performing students attend mathematics classes that offer more advanced mathematics content. Exposure to word problems, which are usually designed by textbook writers as applications of mathematics, are also related to performance, but not as strongly (Figure I.3.4a and Table I.3.2).

In 47 of the 65 participating countries and economies, the opportunity-to-learn variable measuring the frequency of student encounters with applied mathematics tasks was related to PISA performance at either the student or school level or both (Figures I.3.3 and 1.3.5). ${ }^{1}$ Again, the causal nature of the relationship cannot be established. In some countries the relationship is likely to be the result of low-performing students attending programmes and tracks that offer more applied mathematics content.

- Figure 1.3.5

Significance of exposure to applied mathematics

Where exposure is related to performance, at the school and student levels

\begin{tabular}{c|l|l|l}
\hline \multirow{2}{*}{\multicolumn{2}{c|}{}} & \multicolumn{1}{c}{ Significant } & \multicolumn{1}{c}{ Not significant } \\
\cline { 2 - 4 } & \multirow{2}{*}{ Significant } & $\begin{array}{l}\text { School } \\
\text { Bulgaria, Canada, Chile, Colombia, Costa Rica, } \\
\text { Denmark, Finland, Iceland, Ireland, Italy, } \\
\text { Mexico, Peru, Qatar, Romania, Shanghai-China, } \\
\text { Slovak Republic, Switzerland, Thailand, } \\
\text { United Kingdom, Uruguay }\end{array}$ & $\begin{array}{l}\text { Brazil, Croatia, France, Japan, Jordan, Lithuania, } \\
\text { Luxembourg, Macao-China, Malaysia, } \\
\text { Montenegro, New Zealand, Netherlands, } \\
\text { Norway, Serbia, Singapore, Spain, Sweden, } \\
\text { Chinese Taipei, Turkey }\end{array}$ \\
\cline { 2 - 4 } & \multirow{2}{*}{ Not significant } & $\begin{array}{l}\text { Austria, Estonia, Indonesia, Israel, Kazakhstan, } \\
\text { Tunisia, United Arab Emirates }\end{array}$ & $\begin{array}{l}\text { Albania, Argentina, Australia, Belgium, } \\
\text { Czech Republic, Germany, Greece, } \\
\text { Hong Kong-China, Hungary, Korea, } \\
\text { Latvia, Liechtenstein, Poland, Portugal, } \\
\text { Russian Federation, Slovenia, United States, } \\
\text { Viet Nam }\end{array}$ \\
\hline
\end{tabular}

Source: OECD, PISA 2012 Database, Table 1.3.2.

In all 40 countries and economies showing a relationship between applied mathematics and performance at the student level, except Uruguay, Turkey and Shanghai-China, the relationship is curvilinear. This means that the positive relationship between applied mathematics and performance at the student level holds until a certain point, and then it becomes negative. The average of the top-achieving East Asian countries on the applied mathematics index (1.76) falls between "rarely" and "sometimes" on the index. As shown in Figure 1.3.2, the average is just at the inflection point as the curve begins its downward slope. The other 58 countries'/economies' mean places them further down the curve where the decline in performance is greater (Table I.3.1). In 20 of them, namely Uruguay, the United Kingdom, Finland, the Slovak Republic, Thailand, Canada, Ireland, Bulgaria, Chile, Denmark, Peru, Costa Rica, Switzerland, Iceland, Qatar, Colombia, Mexico, Romania, Italy and Shanghai-China there is a relationship between applied mathematics and performance at both the school and student levels (Figure I.3.5). 
Educators and education policy makers tend to agree that the capacity of students to apply mathematical content is central to their success later in life, because modern economies tend to pay people not for what they know but for what they can do with what they know. They often debate the extent to which mathematics that is related to real-world problems should be incorporated into school curricula. Some argue that students learn advanced mathematics content best when studying it in an applied context; others contend that contextual material could detract from the content and therefore exposure to advanced mathematics content with as little contextual material as possible will be most effective in helping students learn and apply the content.

PISA results on the opportunity-to-learn measure do not answer the question directly, but they suggest that it is a matter of balance. It appears that strong mathematics performance in PISA is not only related to opportunities to learn formal mathematics, but also to opportunities to learn applied mathematics. Learning formal mathematics is necessary, but not sufficient by itself. Even with a higher level of opportunities related to formal mathematics, a degree of exposure to applied mathematics problems is, up to some point, positively related to performance.

\section{DIFFERENCES IN OPPORTUNITIES TO LEARN}

Decisions on curriculum content, whether taken at the national, regional, local or school level, have direct consequences on students' academic achievement (Schmidt et al., 2001 and Sykes, Schneider and Plank, 2009). As an integral feature of curricula, opportunities to learn thus fall under the purview of education policy. Given the significant relationship between opportunities to learn and performance, as described above, policy makers can learn through PISA how their decisions about curricula are ultimately reflected in student performance.

Students were asked about the frequency with which they had encountered six types of fairly common real-world mathematics problems during their time at school (see Question 1 at the end of this chapter). The average proportion of students across OECD countries who answered "frequently" ranged from 11.2\% (calculating the power consumption of an electric appliance per week, Figure I.3.6 and Table 1.3.10) to 25.4\% (calculating how many square metres of tiles were needed to cover a floor, Figure I.3.7 and Table 1.3.5). The average proportion of 15-year-olds who rarely or never were taught to do these kinds of tasks ranged from $35.9 \%$ to $57.2 \%$.

Countries varied widely on these measures, though some of this variation may be due to differences in what students in different countries and contexts consider to be frequent. For example, in some countries and economies, namely Hong Kong-China, the Czech Republic, Macao-China and Viet Nam, fewer than $10 \%$ of students say they frequently encounter an applied problem like one that requires them to calculate the taxes imposed when purchasing a computer. In Viet Nam, only $3.6 \%$ of 15 -year-olds say they are frequently exposed to such a problem.

By contrast, $60 \%$ to $61 \%$ of students in OECD and partner countries and economies say they frequently encounter formal mathematics tasks like the two items that involved solving quadratic equations (Tables I.3.7 and I.3.9); and there was much less variation between countries.

PISA also categorised mathematics problems into four types - formal mathematics (Figure I.3.8), word problems (Figure 1.3.9), applied problems in mathematics (Figure 1.3.10), and real-world problems (Figure I.3.11) - in order to more finely distinguish between formal and applied mathematics. PISA found that an average of $68.4 \%$ of students in OECD countries said they frequently encounter formal mathematics tasks (e.g. $2 x+3=7$, and finding the volume of a box) in their mathematics lessons. This proportion varies from a high of $85.4 \%$ in Iceland to a low of $49.0 \%$ in Portugal (Figure I.3.8 and Table I.3.11). Among partner countries and economies, the proportion of students who are frequently exposed to these types of tasks ranges from $78.4 \%$ in Croatia to $43.2 \%$ in Brazil. By contrast, only around $6.5 \%$ of students in OECD countries rarely or never encounter this type of problem.

A second category of mathematics problem includes formal mathematics concepts placed in a word problem of the kind often found in textbooks. These types of word problems do have an "applied" component, but they are often perceived by students as contrived real-world problems. Students can often recognise such word problems as requiring the same computations that they are being asked to perform in the lesson, but with verbiage surrounding the computation. The examples given included purchasing furniture with a discount, and finding the age of someone, given his/her relationship to the age of others. 
- Figure I.3.6 "

Percentage of students who reported having seen applied mathematics problems like "calculating the power consumption of an electric appliance per week" frequently or sometimes

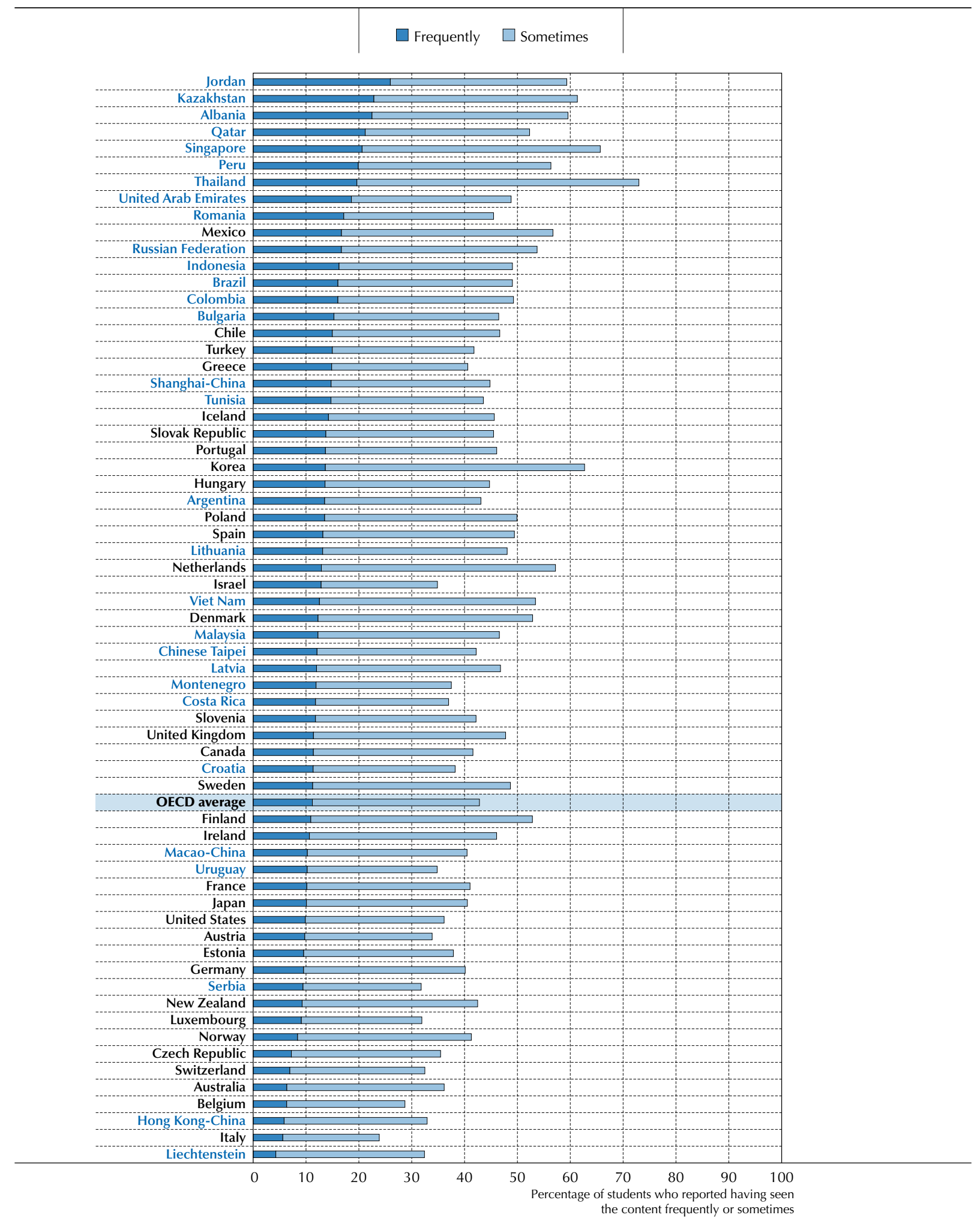

Countries and economies are ranked in descending order of the percentage of students who reported having seen applied mathematics problems, for instance calculating the power consumption of an electronic appliance per week frequently (see Question 1 at the end of this chapter).

Source: OECD, PISA 2012 Database, Table 1.3.10.

StatLink न्ताs $\mathrm{http}: / / \mathrm{dx}$. doi.org/10.1787/888932936427 
- Figure I.3.7

Percentage of students who reported having seen applied mathematics problems like "calculating how many square metres of tiles you need to cover a floor" frequently or sometimes

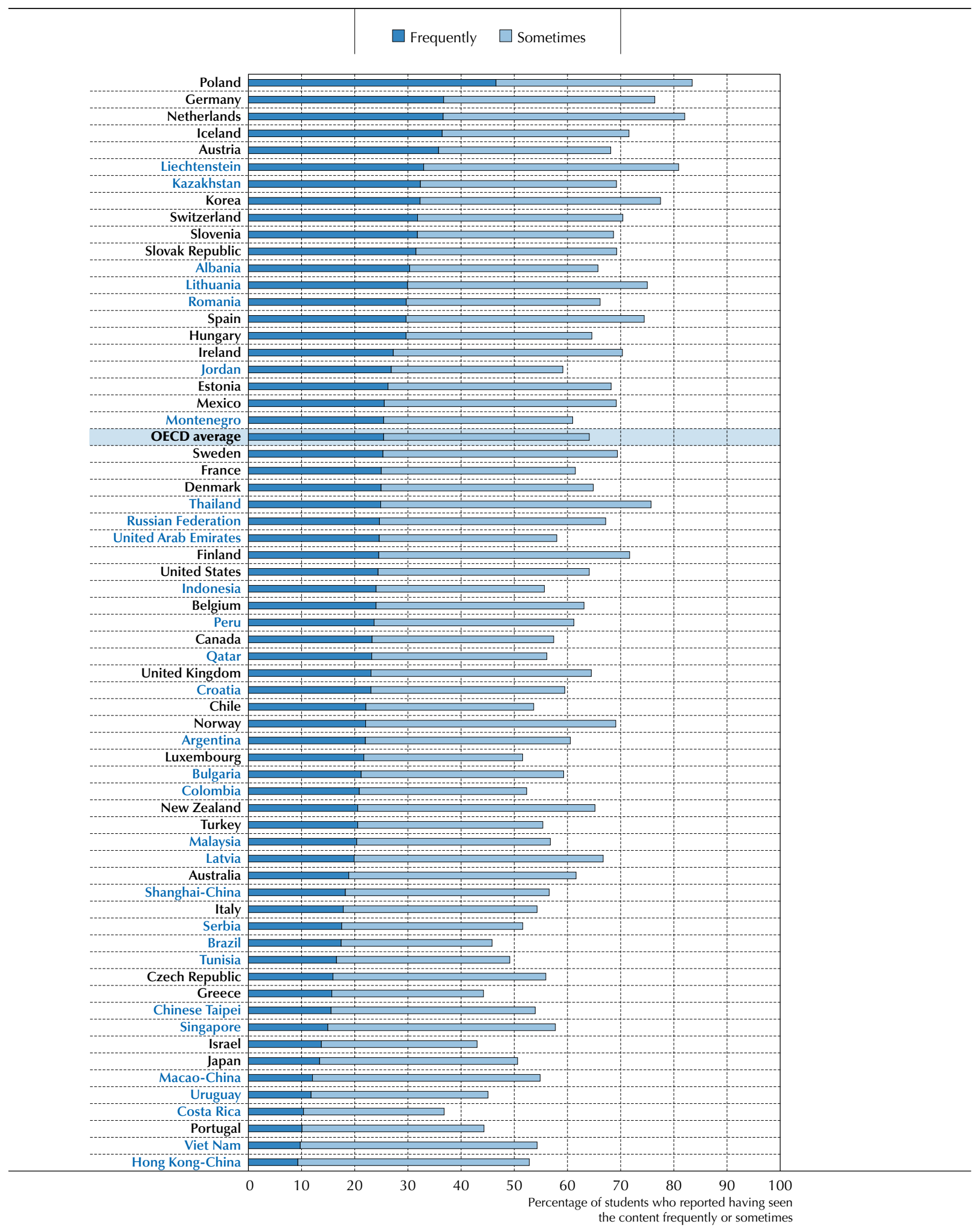

Countries and economies are ranked in descending order of the percentage of students who reported having seen applied mathematics problems, for instance calculating how many square metres of tiles you need to cover a floor, frequently (see Question 1 at the end of this chapter). Source: OECD, PISA 2012 Database, Table I.3.5.

StatLink त्राजम http://dx.doi.org/10.1787/888932936427 
- Figure I.3.8

\section{Percentage of students who reported having seen formal mathematics problems} in their mathematics lessons frequently or sometimes

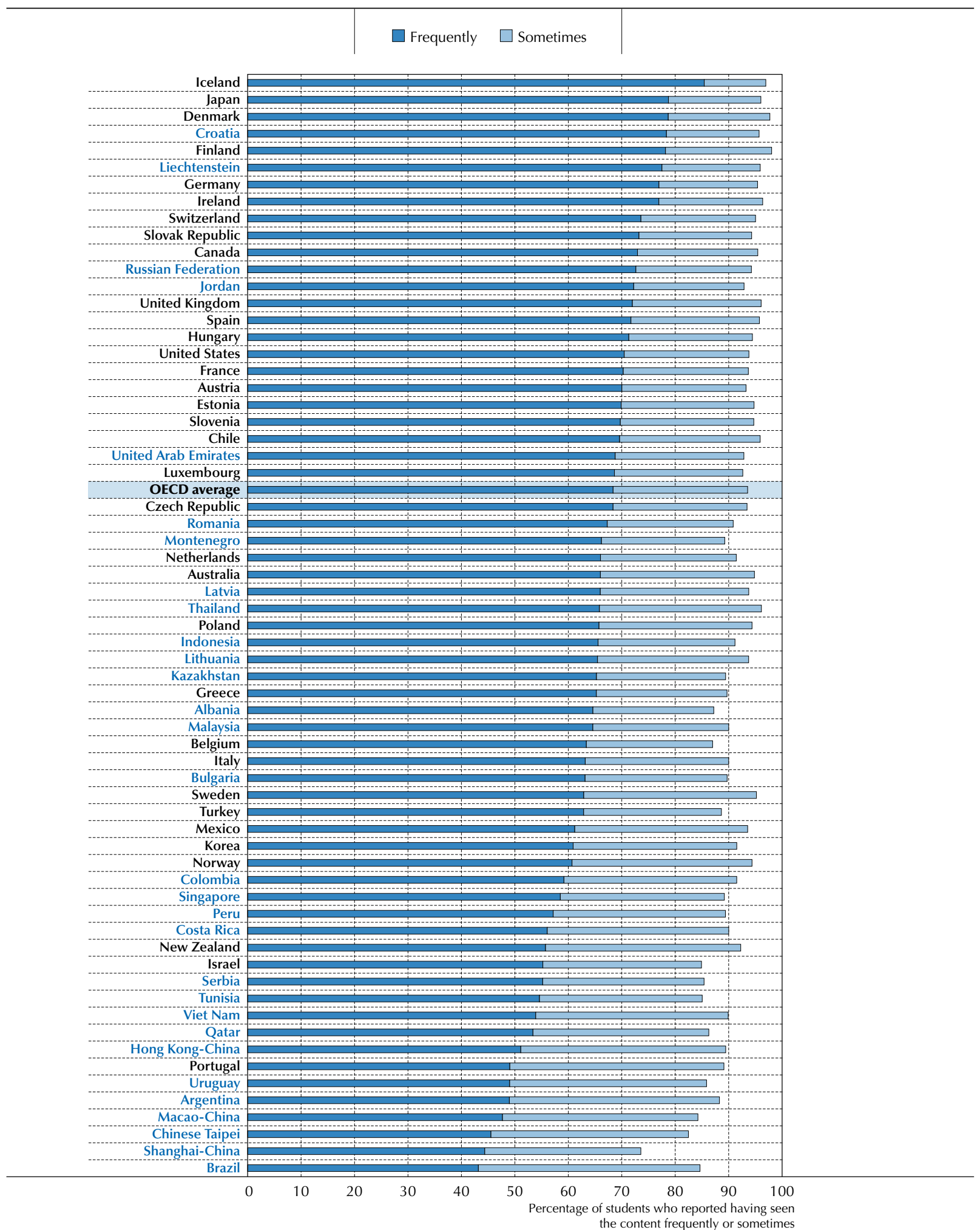

Countries and economies are ranked in descending order of the percentage of students who reported having seen formal mathematics problems, for instance solving an equation or finding the volume of a box, frequently (see Question 4 at the end of this chapter).

Source: OECD, PISA 2012 Database, Table I.3.11.

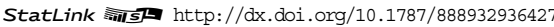


- Figure I.3.9

Percentage of students who reported having seen word problems in their mathematics lessons frequently or sometimes

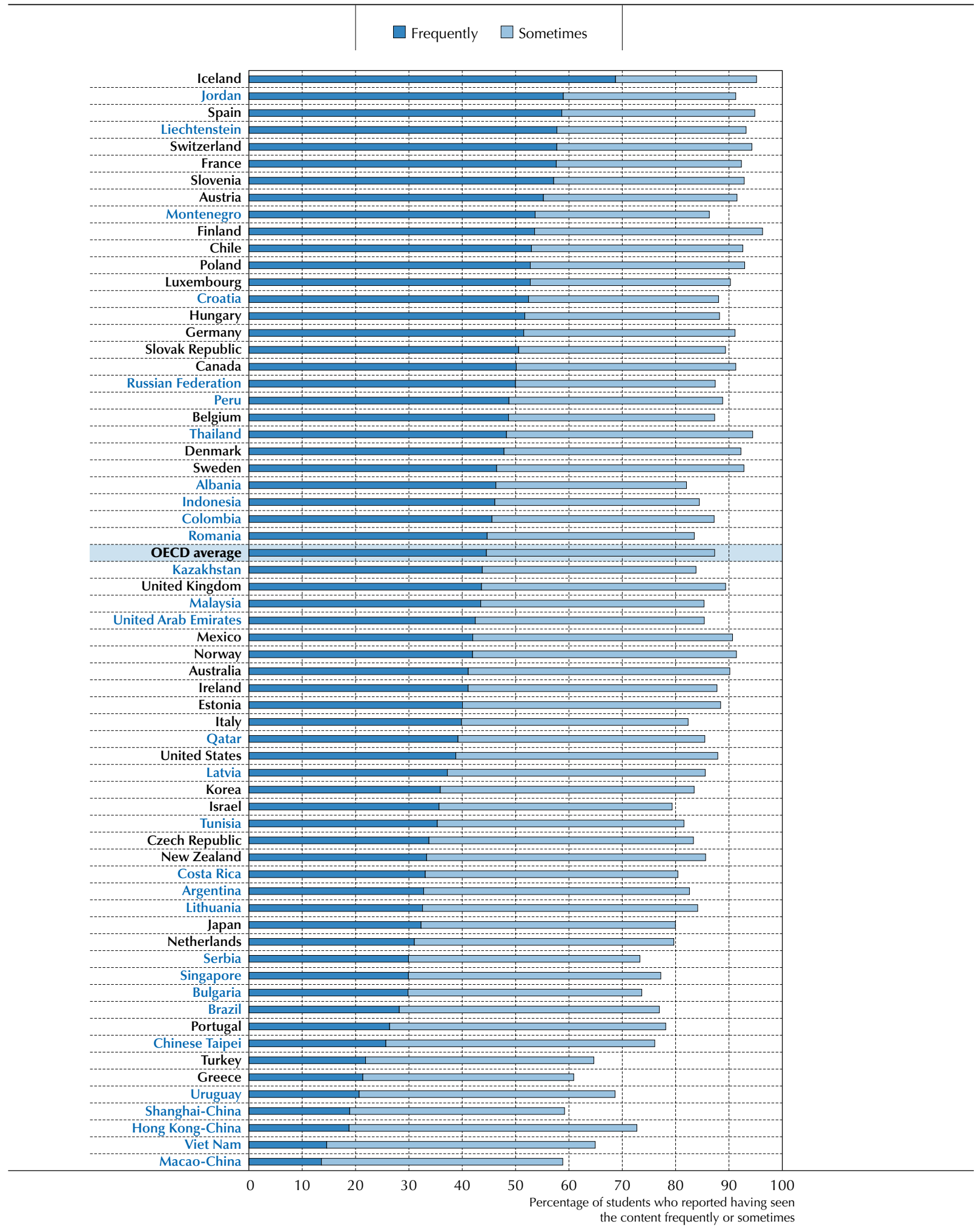

Countries and economies are ranked in descending order of the percentage of students who reported having seen word problems in their mathematics lessons frequently (see Question 3 at the end of this chapter).

Source: OECD, PISA 2012 Database, Table I.3.12.

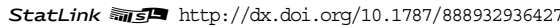


Some $44.5 \%$ of 15 -year-olds in OECD countries say they frequently encounter this type of word problem in their mathematics lessons (Figure I.3.9 and Table 1.3.12), while an average of $12.7 \%$ of students rarely or never encounter such word problems. In France, Spain, Switzerland, Iceland and Slovenia, and in the partner countries Jordan and Liechtenstein, around $60 \%$ of students are exposed to these types of word problems frequently.

In the PISA categorisation of mathematics, two types of applied contexts were studied: mathematics as a context in itself (applied problems in mathematics), and real-world contexts. Across OECD countries, the proportion of students who frequently encounter these two types of problems in their lessons is significantly smaller than the proportion of those who frequently encounter formal mathematics problems and word problems.

Applied problems in mathematics require the use of mathematics theorems, such as finding the height of a pyramid or determining prime numbers - tasks with a primarily mathematical context but that also have more practical applications. Some $34 \%$ of 15 -year-old students in OECD countries say they encounter these problems during their mathematics lessons, but nearly one in four students say they rarely or never encounter these types of problems (Figure 1.3.10 and Table I.3.13). Among OECD countries, only Turkey shows that just over half of its students frequently encounter these types of problems during their lessons. By contrast, in Israel, nearly one in five students never encounters these types of problems in mathematics class.

An average of $21.2 \%$ of students in OECD countries say they frequently encounter mathematics problems that are set in a real-world context; and about $33.6 \%$ of students encounters such problems rarely or never in class (Figure I.3.11 and Table I.3.14). In Mexico, Portugal, Iceland, Chile, Canada, the Netherlands, and in the partner countries and economies Thailand, Jordan, Indonesia, Tunisia, the United Arab Emirates and Colombia, at least 30\% of students frequently encounter these kinds of problems in class.

When looking across the four types of problems in the typology, two observations can be made. First, the typology represents a rough continuum in the percentage of students who are frequently exposed to each type of problem, declining steadily from formal mathematics (68\%) to mathematically-oriented word problems (45\%) to applied problems in mathematics (34\%) to real-world applied problems (21\%) (Figure 1.3.12). At the other end of this distribution, the percentage of students who indicated that they never or rarely have such lessons increased over the same continuum from $7 \%$ to $13 \%$ to $24 \%$ to $34 \%$.

Second, the opportunities to learn the different types of mathematics problems varied greatly among countries - and even more so within countries.

To measure students' familiarity with mathematics content, PISA 2012 asked students how often they had heard of 13 mathematics topics. Tables I.3.15 to I.3.27 show the proportion of students in a country who indicated they had never heard of a particular topic, heard of it once or twice, heard of it a few times, heard of it often, or knew it well. The variation in responses, both across the mathematics topics and across countries, is striking. Considered along with other PISA opportunity-to-learn measures, such as encounters with particular types of problems, these results suggest a wide variation in opportunity to learn - one that is similar to that found in other international mathematics studies, such as the Trends in International Mathematics and Science Study (Mullis et al., 2012).

Assuming familiarity with mathematics topics is related to exposure and by extension to opportunity, the average country results for the 13 topics can be divided into three categories reflecting varying degrees of exposure: the topics with low, medium and high exposure. Fewer than $40 \%$ of students say they "heard often" or "know well" the mathematics topics in the category "low exposure" and more than $60 \%$ in the category "high exposure" do (Table I.3.28). There were clear differences in opportunity to learn different mathematics content.

On average, students identified topics such as linear equations (Figure I.3.13), radicals and polygons as those that they had heard of often and knew well; other topics, such as complex numbers (Figure I.3.14) and exponential functions, which are typically taught in later grades, were much less well known among 15-year-olds (Figure I.3.15). Only 42\% of students in OECD countries reported that they know linear equations well, but when the category "heard of it often" was included, almost two out of three (64.4\%) 15-year-olds say they have heard of them. However, this varies considerably across countries. In Iceland, only $17.8 \%$ of 15 -year-old students say they either know linear equations well or have often heard about them. By contrast, at least $90 \%$ of students in Japan, Korea and Estonia, and in the partner countries and economies Croatia, Macao-China and the Russian Federation have frequent opportunities to learn about linear equations. In the partner country Viet Nam, less than $10 \%$ of students have a similar exposure to linear equations - the core topic of an elementary algebra course. 
- Figure I.3.10

Percentage of students who reported having seen applied problems in mathematics in their mathematics lessons frequently or sometimes

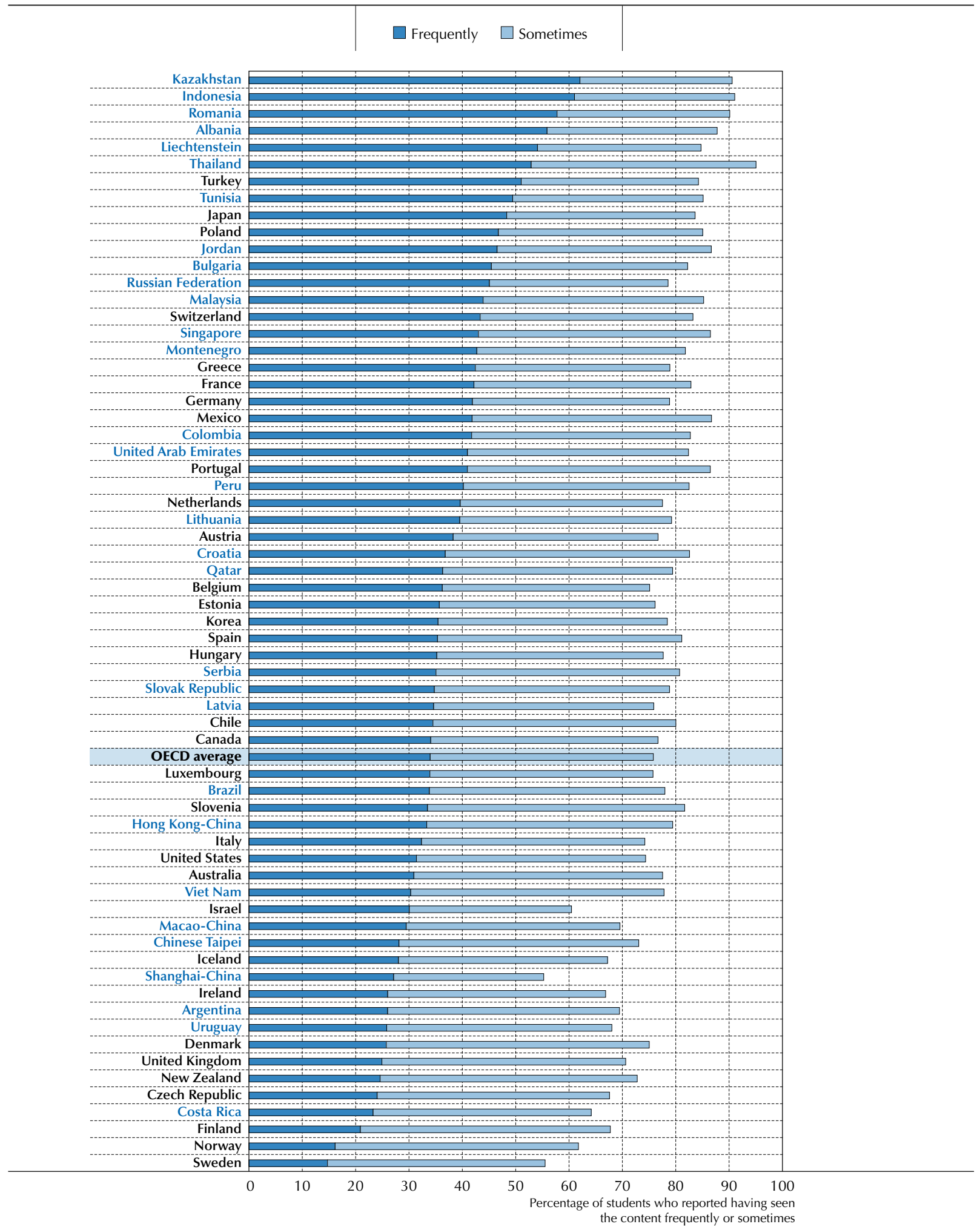

Countries and economies are ranked in descending order of the percentage of students who reported having seen applied problems in mathematics, for instance geometrical theorems or prime numbers, frequently (see Question 5 at the end of this chapter).

Source: OECD, PISA 2012 Database, Table I.3.13.

StatLink तils $\mathrm{\text {http: }} / / \mathrm{dx}$.doi.org/10.1787/888932936427 
- Figure I.3.11

\section{Percentage of students who reported having seen real-world problems in their mathematics lessons frequently or sometimes}

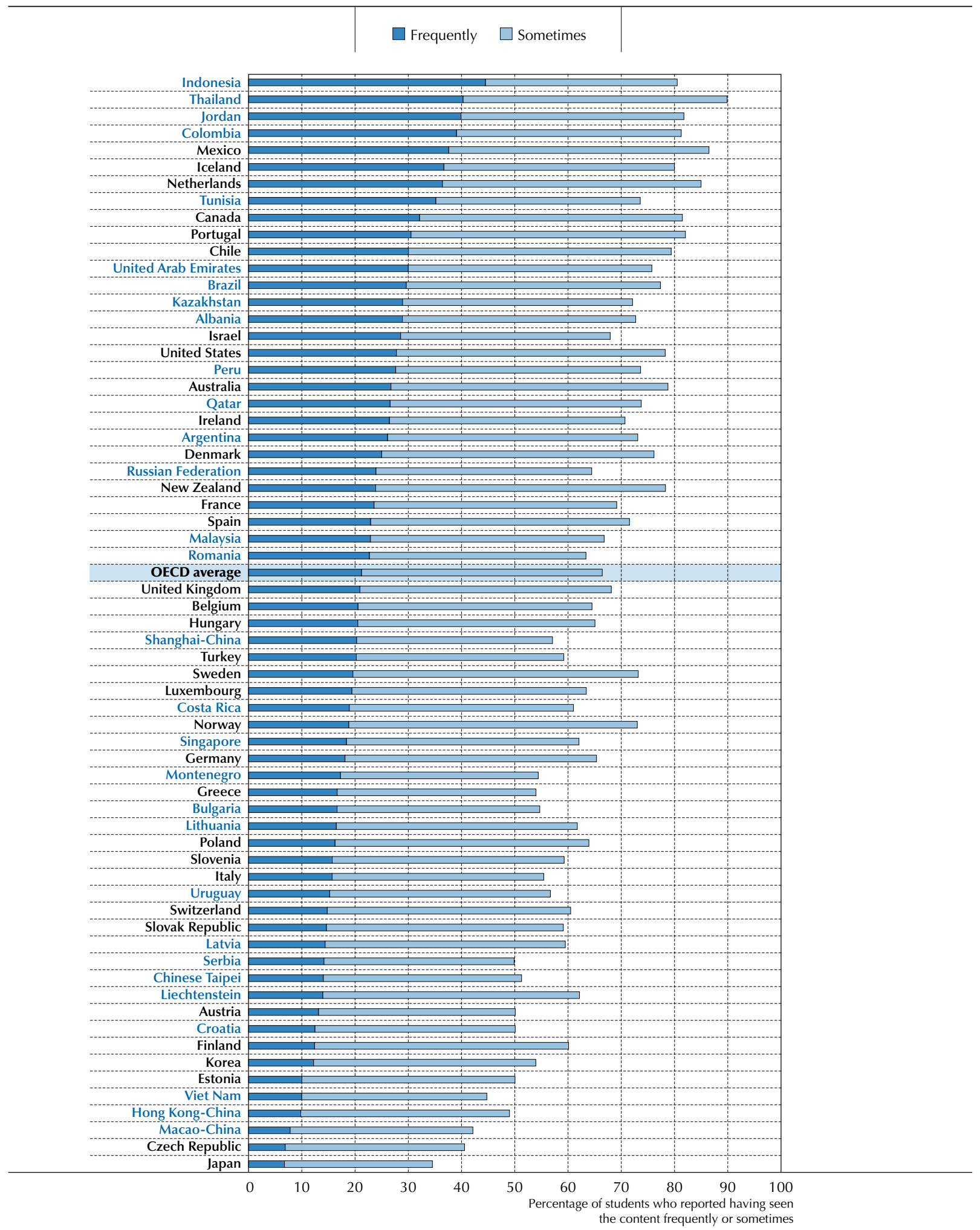

Countries and economies are ranked in descending order of the percentage of students who reported having seen real-world problems frequently (see Question 6 at the end of this chapter).

Source: OECD, PISA 2012 Database, Table I.3.14.

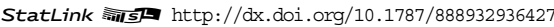


- Figure I.3.12

\section{Student exposure to mathematics problems}

Percentage of students who reported having seen the four types of mathematics problems frequently or sometimes, $O E C D$ average

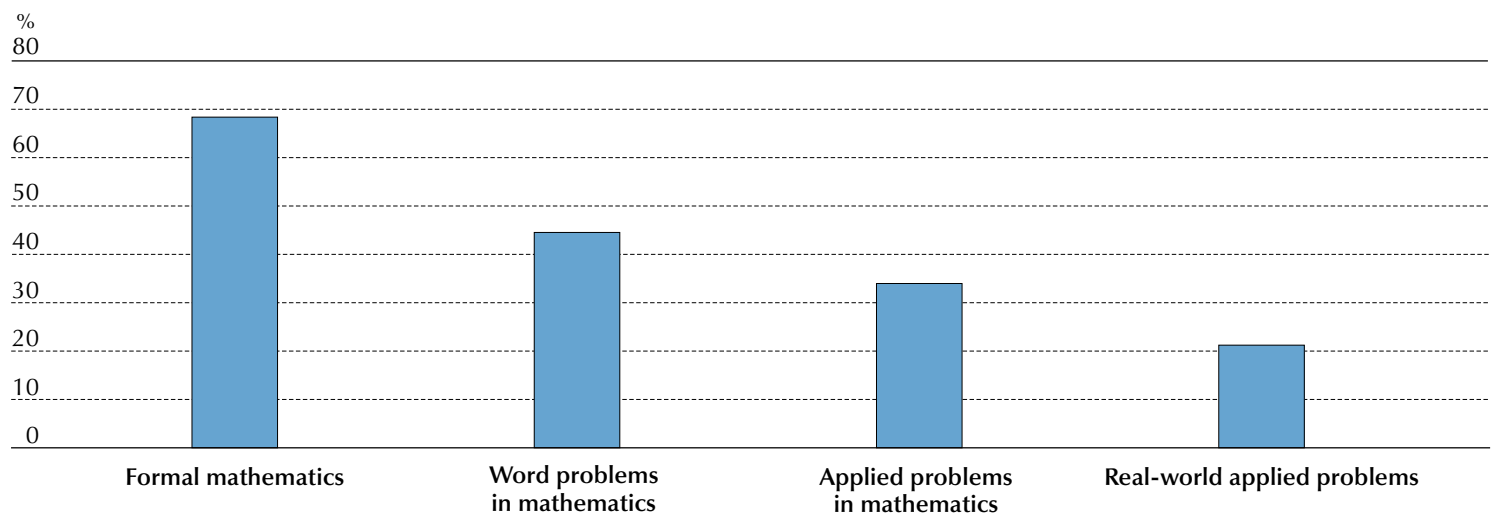

Source: OECD, PISA 2012 Database, Tables I.3.11, I.3.12, I.3.13 and I.3.14.

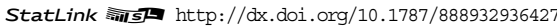

There is also a substantial variation of the familiarity with mathematics topics within some countries, suggesting considerable variability in the implemented curriculum. The point can be illustrated with the algebra topic of quadratic function. For example, in the United Kingdom the distribution of how often students had heard of the topic was almost even across the five response categories (never heard of it, heard of it once or twice, heard of it a few times, heard of it often, or knew it well), with around one in five students self-reporting to fall into each of these categories. A similar type of distribution can be found in Poland, Greece, Colombia and Mexico. For other countries, there is a higher degree of consistency in student reports about their familiarity with mathematics topics. In Shanghai-China, $81 \%$ knew the topic well while fewer than $2 \%$ had never heard of it. Conversely, in Sweden, $63 \%$ of 15 -year-old students had never heard of it while fewer than $5 \%$ knew it well (Figure I.3.16).

OECD countries also show considerable variation on the opportunity-to-learn indices (Figures I.3.1a, b, c and Table I.3.1). The OECD countries Portugal and Mexico had a mean of 2.2 on the applied mathematics index, which implied that, on average, 15-year-old students are sometimes to frequently exposed to these types of problems, while the mean for the Czech Republic was 1.6, between "sometimes" and "rarely". This is a relatively large difference between these countries, given the limited range of the scale. Even larger differences are observed among partner countries and economies: Thailand had a mean of 2.4, indicating that the country's 15-year-olds are between "sometimes" and "frequently" exposed to these types of mathematics problems, while Macao-China shows a mean similar to that of the Czech Republic.

Variations on the formal mathematics index are even larger, with Shanghai-China having a mean of 2.3 (students in these countries encounter such tasks in mathematics class "sometimes" to "frequently") while Sweden shows a mean of 0.8 (meaning students there almost never encounter such problems in their mathematics class).

Using the formal and applied mathematics scales, countries can be categorised into four different groups (Figure I.3.17). The horizontal axis represents the OECD average frequency with which the country's 15-year-olds have the opportunity to learn formal mathematics, while the vertical axis represents the OECD average frequency of the opportunity to learn applied mathematics.

The upper right quadrant shows the countries whose students indicated that, on average, they have more opportunities to learn both applied and formal mathematics. Of the 19 countries in this group, eight of them are OECD countries. Six OECD countries (the United Kingdom, Ireland, Luxembourg, Norway, Sweden and Austria) and three partner countries (Uruguay, Costa Rica and Argentina) are included in the group shown in the lower left quadrant, which includes countries whose students have fewer opportunities to learn both formal and applied mathematics. In partner countries and economies such as Shanghai-China and Macao-China, students reported more opportunities to learn formal mathematics, on average, but fewer opportunities to learn applied mathematics. 
- Figure I.3.13 -

Percentage of students who reported having seen linear equations often or knowing the concept well and understanding it

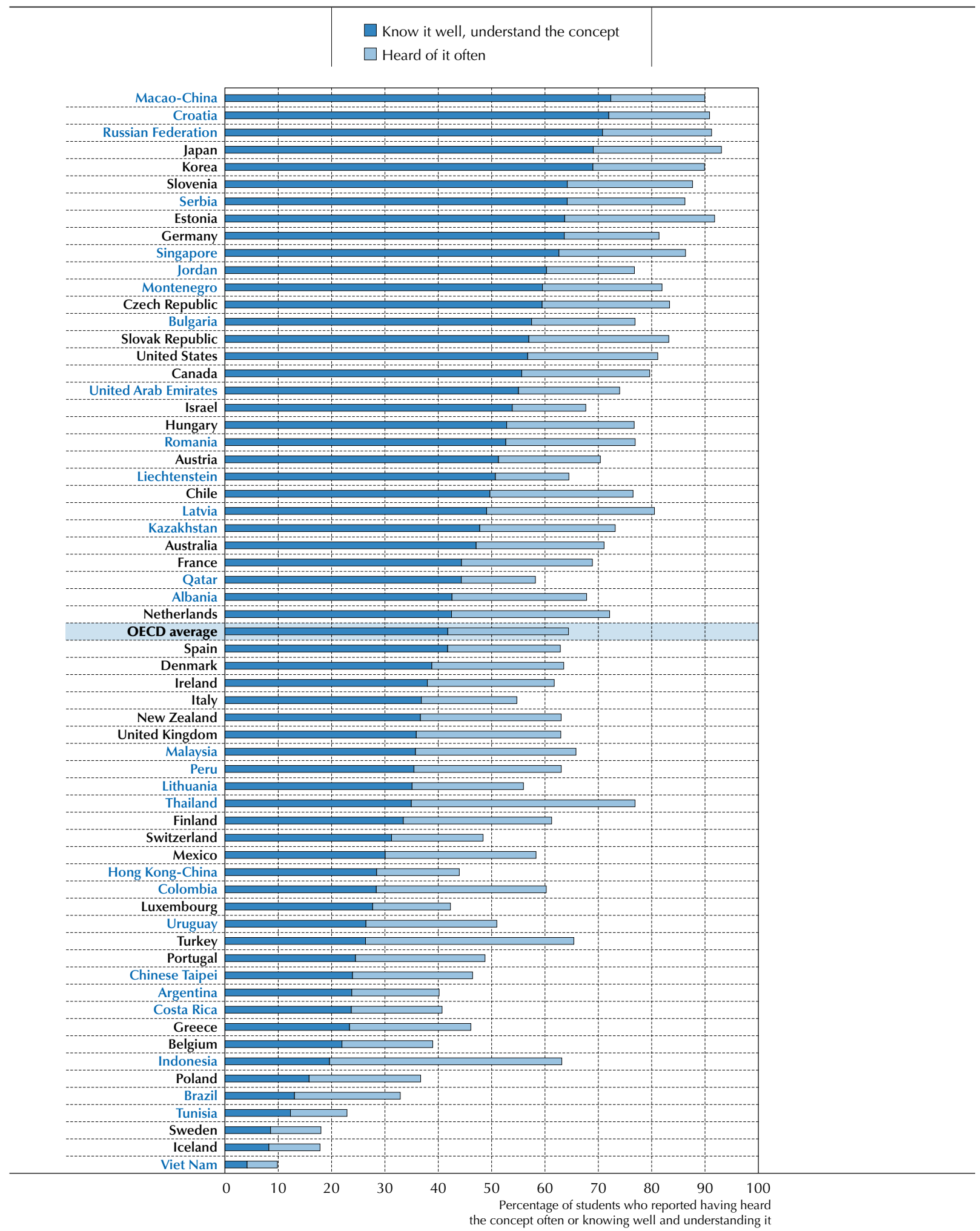

Countries and economies are ranked in descending order of the percentage of students who reported knowing the linear equations concept well and understanding it (see Question 2 at the end of this chapter).

Source: OECD, PISA 2012 Database, Table I.3.18.

StatLink त्नाजम http://dx.doi.org/10.1787/888932936427 


\section{- Figure I.3.14}

Percentage of students who reported having seen complex numbers often or knowing the concept well and understanding it

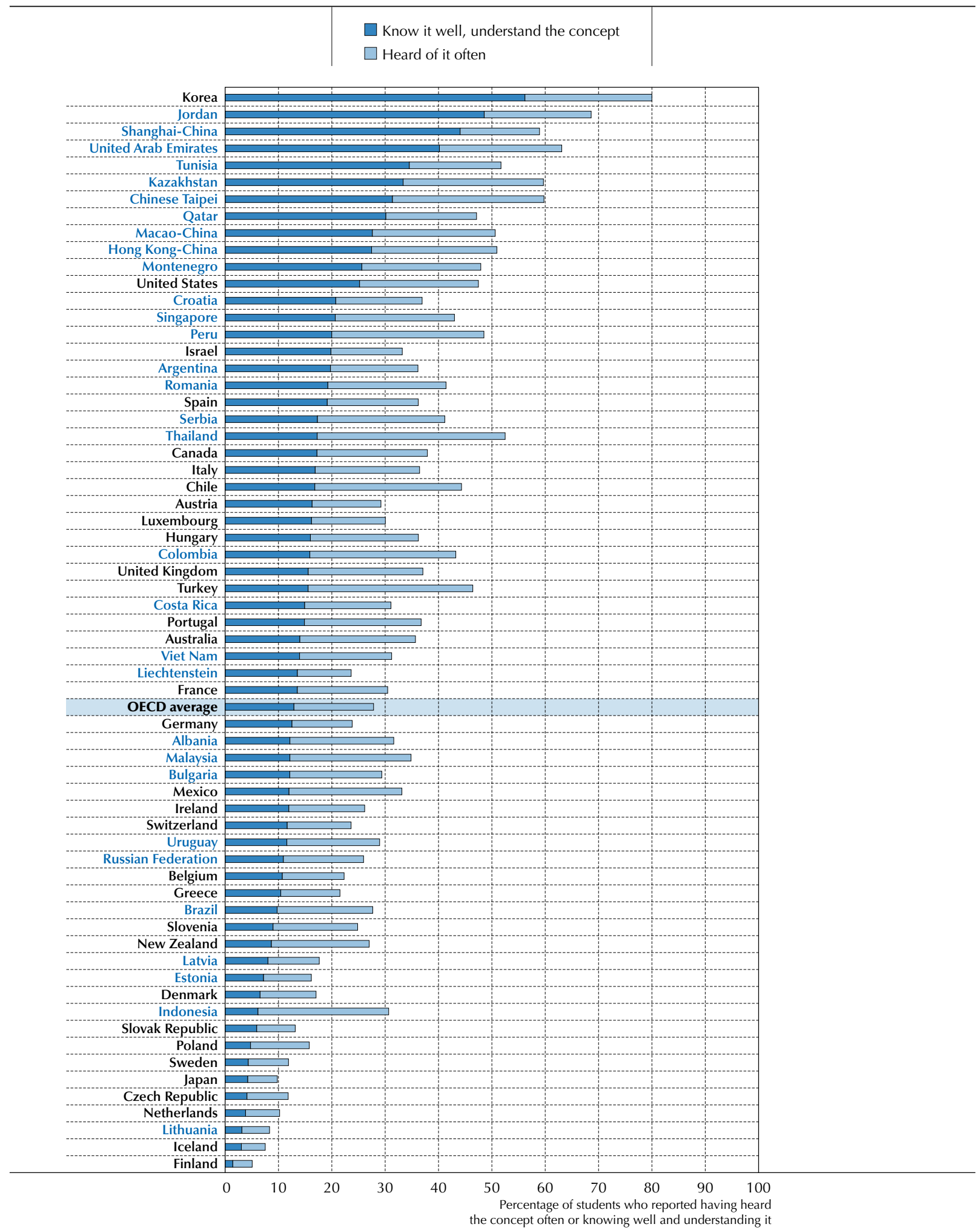

Countries and economies are ranked in descending order of the percentage of students who reported knowing the complex numbers concept well and understanding it (see Question 2 at the end of this chapter).

Source: OECD, PISA 2012 Database, Table I.3.20.

StatLink त्राजय http://dx.doi.org/10.1787/888932936427 
- Figure I.3.15 -

Percentage of students who reported having seen exponential functions often or knowing the concept well and understanding it

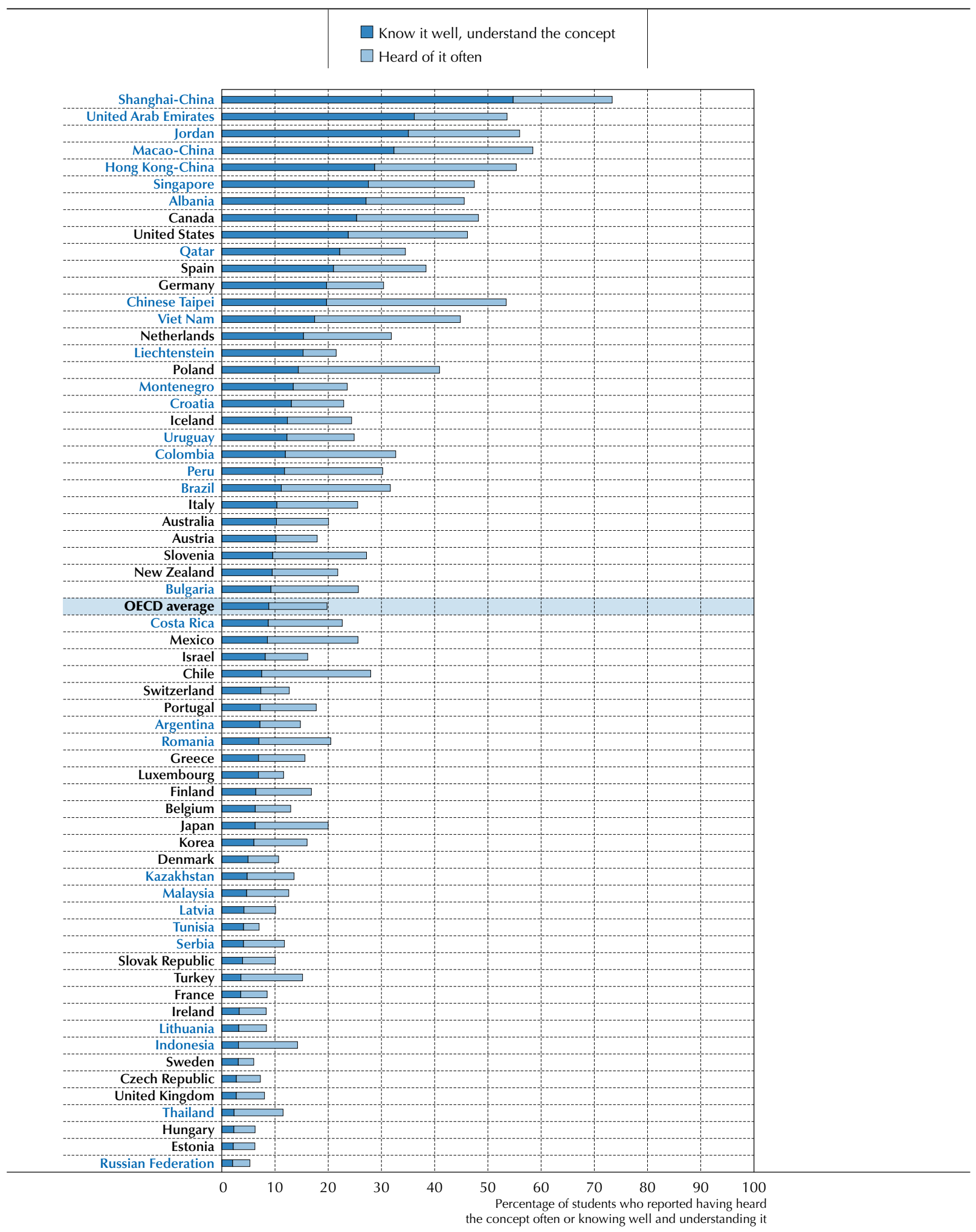

Countries and economies are ranked in descending order of the percentage of students who reported knowing the exponential functions concept well and understanding it (see Question 2 at the end of this chapter).

Source: OECD, PISA 2012 Database, Table I.3.15.

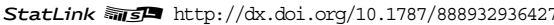




\section{- Figure I.3.16}

\section{Percentage of students who reported having seen quadratic functions often} or knowing the concept well and understanding it

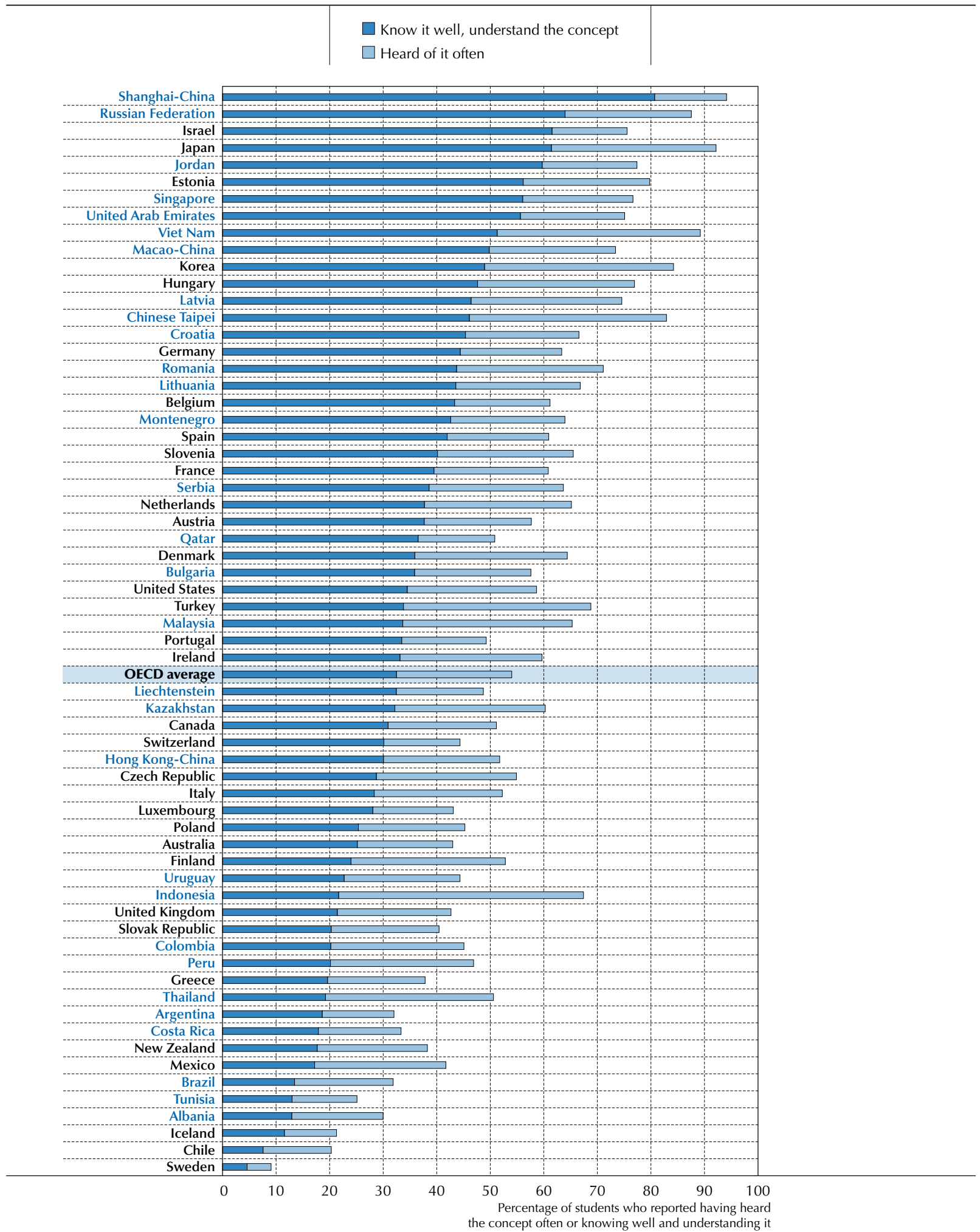

Countries and economies are ranked in descending order of the percentage of students who reported knowing the quadratic functions concept well and understanding it (see Question 2 at the end of this chapter).

Source: OECD, PISA 2012 Database, Table I.3.17.

StatLink त्ञाज http://dx.doi.org/10.1787/888932936427 
- Figure I.3.17

\section{Exposure to applied mathematics vs. exposure to formal mathematics}

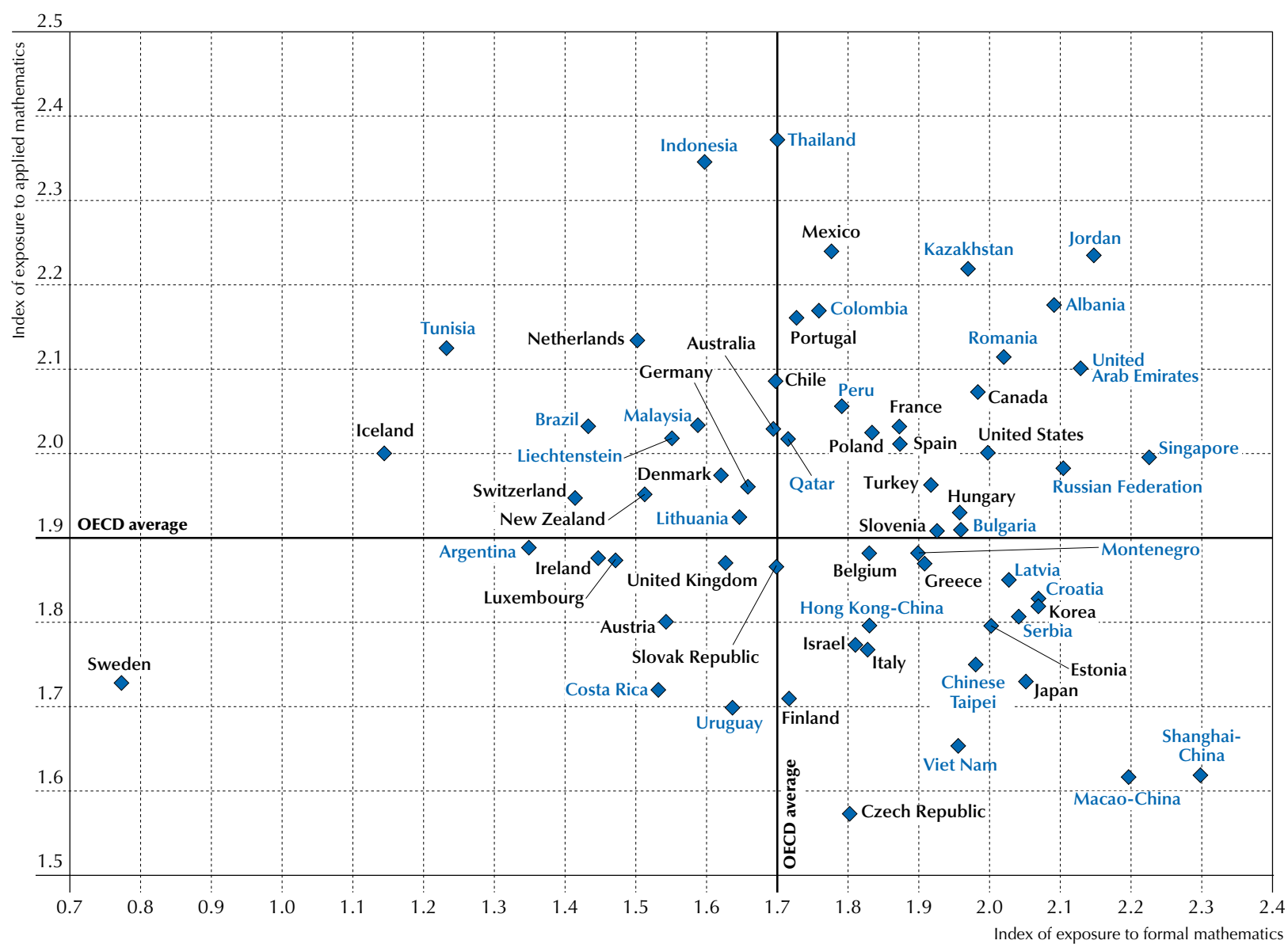

Source: OECD, PISA 2012 Database, Tables 1.3.1.

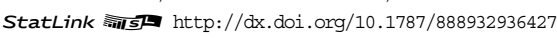




\section{QUESTIONS USED FOR THE CONSTRUCTION OF THE THREE OPPORTUNITY TO LEARN INDICES}

Six questions were used from the Student Questionnaire to cover both the content and the time aspects of the opportunity to learn. These questions are shown below.

\section{Question 1}

How often have you encountered the following types of mathematics tasks during your time at school? (Please tick only one box on each row.)

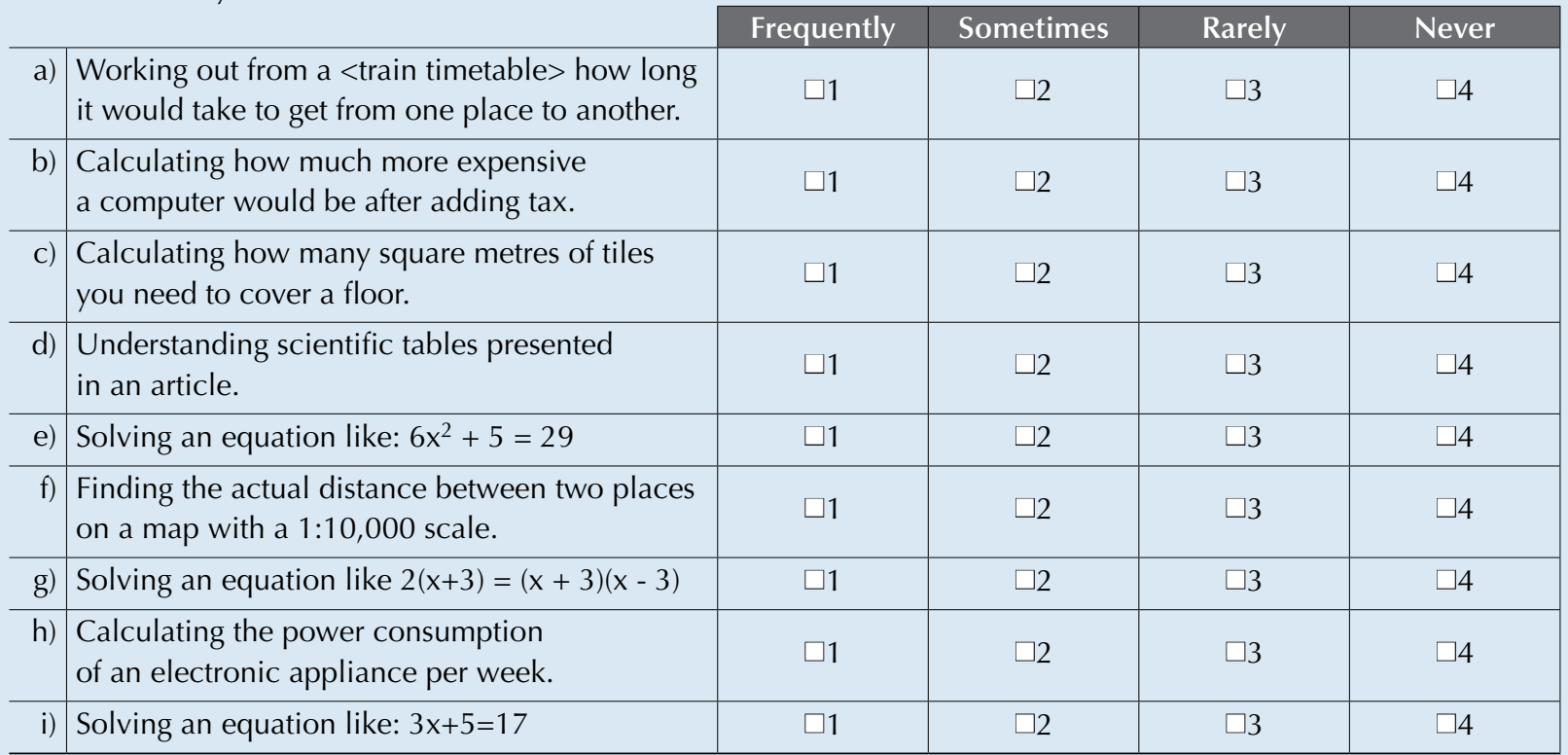

\section{Question 2}

Thinking about mathematical concepts: how familiar are you with the following terms? (Please tick only one box in each row.)

\begin{tabular}{|c|c|c|c|c|}
\hline $\begin{array}{c}\text { Never } \\
\text { heard of it }\end{array}$ & $\begin{array}{c}\text { Heard of it } \\
\text { once or twice }\end{array}$ & $\begin{array}{c}\text { Heard of it } \\
\text { a few times }\end{array}$ & $\begin{array}{c}\text { Heard of it } \\
\text { often }\end{array}$ & $\begin{array}{c}\text { Know it well, } \\
\text { understand } \\
\text { the concept }\end{array}$ \\
\hline$\square 1$ & $\sqcup 2$ & $\square 3$ & $\square 4$ & $\square 5$ \\
\hline$\square 1$ & $\square 2$ & $\square 3$ & $\square 4$ & $\square 5$ \\
\hline$\square 1$ & $\square 2$ & $\square 3$ & $\square 4$ & $\square 5$ \\
\hline$\square 1$ & $\square 2$ & $\square 3$ & $\square 4$ & $\square 5$ \\
\hline$\square 1$ & $\square 2$ & $\square 3$ & $\square 4$ & $\square 5$ \\
\hline$\square 1$ & $\square 2$ & $\square 3$ & $\square 4$ & $\square 5$ \\
\hline$\square 1$ & $\square 2$ & $\square 3$ & $\square 4$ & $\square 5$ \\
\hline$\square 1$ & $\square 2$ & $\square 3$ & $\square 4$ & $\square 5$ \\
\hline$\square 1$ & $\square 2$ & $\square 3$ & $\square 4$ & $\square 5$ \\
\hline$\square 1$ & $\square 2$ & $\square 3$ & $\square 4$ & $\square 5$ \\
\hline$\square 1$ & $\square 2$ & $\square 3$ & $\square 4$ & $\square 5$ \\
\hline$\square 1$ & $\square 2$ & $\square 3$ & $\square 4$ & $\square 5$ \\
\hline$\square 1$ & $\square 2$ & $\square 3$ & $\square 4$ & $\square 5$ \\
\hline
\end{tabular}

The next four questions are about students' experience with different kinds of mathematics problems at school. They include some descriptions of problems and dark blue-coloured boxes, each containing a mathematics problem. The students had to read each problem but did not have to solve it. 


\section{Question 3}

In the box is a series of problems. Each requires you to understand a problem written in text and perform the appropriate calculations. Usually the problem talks about practical situations, but the numbers and people and places mentioned are made up. All the information you need is given. Here are two examples:

1. $<$ Ann $>$ is two years older than $<$ Betty $>$ and $<$ Betty $>$ is four times as old as $<$ Sam $>$. When $<$ Betty $>$ is 30 , how old is $<$ Sam $>$ ?

2. $\mathrm{Mr}<$ Smith $>$ bought a television and a bed. The television cost $<\$ 625>$ but he got a $10 \%$ discount. The bed cost $<\$ 200>$. He paid $<\$ 20>$ for delivery. How much money did Mr $<$ Smith $>$ spend?

We want to know about your experience with these types of word problems at school. Do not solve them!

(Please tick only one box in each row.)

a) How often have you encountered these types of problems in your mathematics lessons?

b) How often have you encountered these types of problems in the tests you have taken at school?

\begin{tabular}{|c|c|c|c|}
\hline Frequently & Sometimes & Rarely & Never \\
\hline$\square 1$ & $\square 2$ & $\square 3$ & $\square 4$ \\
\hline$\sqcup 1$ & $\square 2$ & $\square 3$ & $\square 4$ \\
\hline
\end{tabular}

\section{Question 4}

Below are examples of another set of mathematical skills.

1) Solve $2 x+3=7$.

2) Find the volume of a box with sides $3 \mathrm{~m}, 4 \mathrm{~m}$ and $5 \mathrm{~m}$.

We want to know about your experience with these types of problems at school. Do not solve them! (Please tick only one box in each row.)

a) How often have you encountered these types of problems in your mathematics lessons?

b) How often have you encountered these types of problems in the tests you have taken at school?

\begin{tabular}{|c|c|c|c|}
\hline Frequently & Sometimes & Rarely & Never \\
$\square 1$ & $\square 2$ & $\square 3$ & $\square 4$ \\
$\square 1$ & $\square 2$ & $\square 3$ & $\square 4$ \\
\hline
\end{tabular}

\section{Question 5}

In the next type of problem, you have to use mathematical knowledge and draw conclusions. There is no practical application provided. Here are two examples.

1) Here you need to use geometrical theorems:

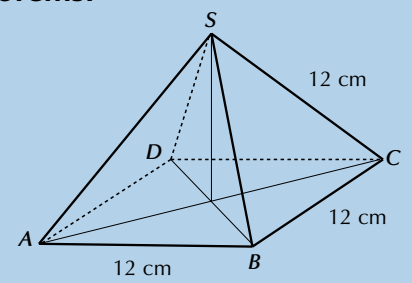

Determine the height of the pyramid.

\section{2) Here you have to know what a prime number is:}

If $n$ is any number: can $(n+1)^{2}$ be a prime number?

We want to know about your experience with these types of problems at school. Do not solve them! (Please tick only one box in each row.)

a) How often have you encountered these types of problems in your mathematics lessons?

b) How often have you encountered these types of problems in the tests you have taken at school?

\begin{tabular}{|c|c|c|c|}
\hline Frequently & Sometimes & Rarely & Never \\
$\square 1$ & $\square 2$ & $\square 3$ & $\square 4$ \\
$\square 1$ & $\square 2$ & $\square 3$ & $\square 4$ \\
\hline
\end{tabular}




\section{Question 6}

In this type of problem, you have to apply suitable mathematical knowledge to find a useful answer to a problem that arises in everyday life or work. The data and information are about real situations. Here are two examples.

\section{Example 1}

A TV reporter says "This graph shows that there is a huge increase in the number of robberies from 1998 to $1999 . "$

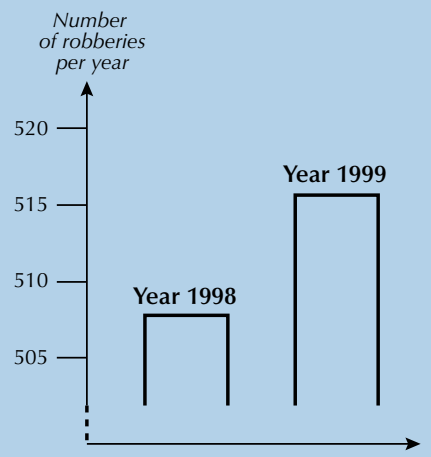

\section{Example 2}

For years the relationship between a person's recommended maximum heart rate and the person's age was described by the following formula:

Recommended maximum heart rate $=220-$ age

Recent research showed that this formula should be modified slightly. The new formula is as follows:

Recommended maximum heart rate $=208-(0.7 \times$ age $)$

From which age onwards does the recommended maximum heart rate increase as a result of the introduction of the new formula? Show your work.

\section{We want to know about your experience with these types of problems at school. Do not solve them!}

(Please check only one box in each row.)

a) How often have you encountered these types of problems in your mathematics lessons?

b) How often have you encountered these types of problems in the tests you have taken at school?

\begin{tabular}{|c|c|c|c|}
\hline Frequently & Sometimes & Rarely & Never \\
$\square 1$ & $\square 2$ & $\square 3$ & $\square 4$ \\
\hline 1 & $\sqcup 2$ & $\square 3$ & $\square 4$ \\
\hline
\end{tabular}

\section{THE THREE OPPORTUNITY TO LEARN INDICES}

From these questions, three indices were constructed:

\section{- The index of exposure to word problems}

This index was coded using the frequency choices for the word-problem type of task (Question 3) as follows:

frequently $=3$, sometimes and rarely $=1$, and never $=0$.

\section{- The index of exposure to applied mathematics}

This index was constructed as the mean of the applied tasks involving both the mathematics contexts (Question 5) and the real-world contexts (Question 6). Each was separately scaled as:

frequently $=3$, sometimes $=2$, rarely $=1$, and never $=0$.

- The index of exposure to formal mathematics

This index was created as the average of three scales.

- Two separate scales were constructed using the item asking for the degree of the student's familiarity with 7 of the 13 mathematics content areas (Question 2). The five response categories reflecting the degree to which they had heard of the topic were scaled 0 to 4 with 0 representing "never heard of it" 4 representing they "knew it well". 
The frequency codes for the three topics - exponential functions, quadratic functions, and linear equations - were averaged to define familiarity with algebra. Similarly, the average of four topics defined a geometry scale, including vectors, polygons, congruent figures, and cosines.

- The third scale was derived from the item where students indicated how often they had been confronted with problems defined as formal mathematics (Question 4). The frequency categories were coded as "frequently", "sometimes", and "rarely" equalling 1 and "never" equal to 0, resulting in a dichotomous variable. The algebra, geometry and formal mathematics tasks were averaged to form the index "formal mathematics", which ranged in values from 0 to 3 , similar to the other three indices. 


\section{Note}

1. The 18 countries/economies that show no relationship between the frequency of student encounters with applied mathematics problems and the performance of 15-year-olds on PISA are the United States, Poland, Hong Kong-China, Greece, Albania, Latvia, Germany, the Czech Republic, Hungary, Australia, Belgium, Argentina, Slovenia, Portugal, Liechtenstein, Korea, the Russian Federation and Viet Nam.

\section{References}

Carroll, J.B. (1963), “A model of school learning", Teachers College Record, 64(8), pp. 723-733.

OECD (2013), PISA 2012 Assessment and Analytical Framework: Mathematics, Reading, Science, Problem Solving and Financial Literacy, OECD Publishing. http://dx.doi.org/10.1787/9789264190511-en

Mullis, I.V.S., et al. (2012), TIMSS 2011 International Results in Mathematics, Chestnut Hill, Boston College, Massachusetts.

Schmidt, W.H., et al. (2001), Why Schools Matter: A Cross-national Comparison of Curriculum and Learning, Jossey-Bass, San Francisco.

Sykes, G., B. Schneider and D.N. Plank (2009), Handbook of Education Policy Research, Routledge, New York.

Wiley, D.E. and A. Harnischfeger (1974), "Explosion of a myth: Quantity of schooling and exposure to instruction, major educational vehicles", Educational Researcher, 3(4), pp. 7-12. 


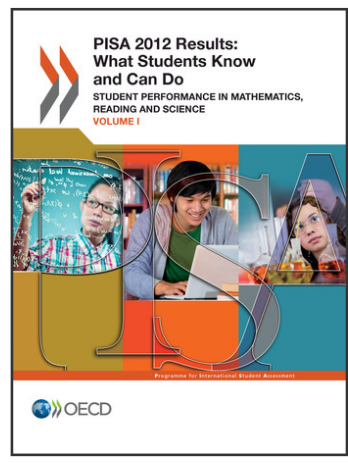

\section{From: \\ PISA 2012 Results: What Students Know and Can Do (Volume I)}

Student Performance in Mathematics, Reading and Science

Access the complete publication at:

https://doi.org/10.1787/9789264201118-en

\section{Please cite this chapter as:}

OECD (2013), "Chapter 3. Measuring Opportunities to Learn Mathematics", in PISA 2012 Results: What Students Know and Can Do (Volume I): Student Performance in Mathematics, Reading and Science, OECD Publishing, Paris.

DOI: https://doi.org/10.1787/9789264201118-6-en

This work is published under the responsibility of the Secretary-General of the OECD. The opinions expressed and arguments employed herein do not necessarily reflect the official views of OECD member countries.

This document and any map included herein are without prejudice to the status of or sovereignty over any territory, to the delimitation of international frontiers and boundaries and to the name of any territory, city or area.

You can copy, download or print OECD content for your own use, and you can include excerpts from OECD publications, databases and multimedia products in your own documents, presentations, blogs, websites and teaching materials, provided that suitable acknowledgment of OECD as source and copyright owner is given. All requests for public or commercial use and translation rights should be submitted to rights@oecd.org. Requests for permission to photocopy portions of this material for public or commercial use shall be addressed directly to the Copyright Clearance Center (CCC) at info@copyright.com or the Centre français d'exploitation du droit de copie (CFC) at contact@cfcopies.com. 